\title{
The neuropsychopharmacology of action inhibition: cross-species translation of the stop-signal and go/no-go tasks
}

\author{
Dawn M. Eagle • Andrea Bari • Trevor W. Robbins
}

Received: 10 July 2007 / Accepted: 26 February 2008 / Published online: 10 June 2008

(C) Springer-Verlag 2008

\begin{abstract}
Background and rationale The term 'action inhibition' encapsulates the ability to prevent any form of planned physical response. Growing evidence suggests that different 'stages' or even subtypes of action inhibition activate subtly different neuropharmacological and neuroanatomical processes.

Objectives In this review, we present evidence from two commonly used and apparently similar behavioural tests, the stop-signal task and the go/no-go task, to determine if these have similar neuroanatomical and neurochemical modulation.

Results Whilst performance of the stop-signal and go/no-go tasks is modulated across only subtly different anatomical networks, serotonin (5-HT) is strongly implicated in inhibitory control on the go/no-go but not the stop-signal task, whereas the stop-signal reaction time appears more sensitive to the action of noradrenaline.

Conclusions There is clear neuropharmacological and neuroanatomical evidence that stop-signal and go/no-go tasks represent different forms of action inhibition. This evidence translates with remarkable consistency across species. We discuss the possible implications of this evidence with respect to the development of novel therapeutic treatments for disorders in which inhibitory deficits are prominent and debilitating.
\end{abstract}

Keywords Impulsivity · Human · Rat · Dopamine ·

Noradrenaline $\cdot$ Serotonin

D. M. Eagle $(\varangle) \cdot$ A. Bari $\cdot$ T. W. Robbins

Department of Experimental Psychology,

University of Cambridge,

Downing Site,

Cambridge, CB2 3EB, UK

e-mail: d.eagle@psychol.cam.ac.uk

\section{Introduction}

'Action inhibition' may be defined as the inhibition of a pre-planned physical response. Without such an ability to inhibit actions, it would be impossible to perform even the simplest of everyday tasks. The more generalised term 'inhibition' has been widely used in neuroscience for over 100 years (Smith 1992 in Aron 2007), and in one sense, can be viewed as a critical executive-control mechanism, regulating a wide range of cognitive and motor processes that are required to prevent the execution of any action, for example, resisting temptation, delay of gratification, Pavlovian conditioned inhibition, motor inhibition and impulse control (Aron 2007; Harnishfeger 1995; Lister et al. 1996). Whilst recent debate has led to dispute over the precise definitions of behavioural and cognitive processes within the concept of 'inhibition', the phenomenon of 'action inhibition' is widely accepted within the psychological literature as an indisputable and plausible form of inhibition (MacLeod et al. 2003).

\section{The unitary concept of 'action inhibition'}

Action inhibition may define one specific neural process, that of simply inhibiting a pre-planned motor response or it may reflect a set of subtly different processes that are dissociable at the neural level: attending to, and interpreting, signals to inhibit; making decisions based on those signals and other internal and external cues; selecting an appropriate inhibitory action and successfully executing a motor action that counteracts the pre-planned motor response. From a clinical perspective, such a deconstruction of action inhibition into behavioural subtypes would be important if it were to reveal critical differences between 
disorders showing so-called action-inhibition deficits. This might be predicted in the light of studies of impulsive behaviour, which have deconstructed a unitary concept of 'impulsivity' into several distinct behavioural subtypes, each of which can be defined pharmacologically and anatomically (Chamberlain and Sahakian 2007; Robinson et al. 2007; Winstanley et al. 2004a; Winstanley et al. 2006).

Deficient action inhibition has been characterised in a number of disorders, including attention deficit and hyperactivity disorder (ADHD), Parkinson's disease, schizophrenia, obsessive-compulsive disorder and chronic substance abuse (e.g. cocaine, amphetamine, methamphetamine), and is also seen as a useful behavioural marker of genetic risk factors (Aron 2007; Aron and Poldrack 2005; Bellgrove et al. 2006; Durston et al. 2008; Fillmore and Rush 2002; Fillmore et al. 2002, 2006; Gauggel et al. 2004; Monterosso et al. 2005; Nigg et al. 2004; Oosterlaan et al. 1998; Penades et al. 2007; Rubia et al. 1998, 2005b, 2007; Schachar et al. 2007; Schachar et al. 1995; van den Wildenberg et al. 2006). Indeed, impaired action inhibition is often considered as the core deficit in ADHD (e.g. Barkley 1997), and at the very least, one of the key executive function deficits within an integrative model of the ADHD spectrum (e.g. Castellanos et al. 2006). Test batteries that include measures of action inhibition (stopsignal and go/no-go tasks) are extensively used in ADHD research (Rubia et al. 2007). However, the majority of studies define a unitary action-inhibition deficit using a range of diagnostic tasks, such as go/no-go, stop-signal and reversal-learning tasks, that are used interchangeably, but that potentially tap into different fundamental mechanisms. Underlying pharmacological differences between actioninhibition subtypes may dictate the efficacy of a particular treatment regime and may explain why a drug that is effective at treating inhibitory deficits in some people is ineffective in others. In this review, we discuss evidence that defines separate processes within the global concept of action inhibition and show, using evidence that translates from rodent to human tasks, that these forms of inhibition are mediated via different anatomical and pharmacological substrates within the brain. This may have significant implications for the development of novel therapies for disorders such as ADHD in which action-inhibition deficits are prominent.

\section{'Action restraint' and 'action cancellation'}

Recently, Schachar et al. (2007) defined two forms of action inhibition: 'action restraint' and 'action cancellation'. With both forms of inhibition acting on pre-planned motor actions, action restraint describes the inhibition of the motor response before that response has been started. Action restraint is studied in tasks such as the go/no-go task and the main focus of interest is the ability or failure to withhold from responding (percentage successful inhibition, commission errors, false alarms, etc.). Action cancellation describes the inhibition of a motor response during its execution and is studied using the stop-signal task. The key component of the stop-signal task is the stop-signal reaction time (SSRT), which is an estimate of the time taken for a subject to attend to, process and complete an inhibitory response to the stop signal. The 'race' model (Logan 1994; Logan and Cowan 1984) provides a theoretical framework that enables the estimation of the end point of this response (the action of inhibition) for which there is no physical outcome (Appendix).

Superficially, there appears only a semantic difference between these forms of inhibition, and indeed, across the literature, particularly in studies of ADHD, go/no-go and stop-signal tasks are usually used interchangeably to describe dysfunctional action inhibition (e.g. Aron 2007; Aron et al. 2004) on the assumption that they reflect a common process and neural substrate. Indeed, the general formats of stop-signal and go/no-go tasks in behavioural research are often similar or identical with the only difference being the position of the stop signal relative to the go response (Fig. 1). Both tasks are based on repeated performance of a motor response, the 'go' response, which may be a key/lever press or touch-screen response to a visual stimulus. In a subset of trials, the subject receives a 'stop' signal (either visual or auditory) that informs the subject to inhibit the 'go' response, after which the subject must inhibit performance of the go response for a predefined time period. SSRT (the time required to attend to, process and complete an inhibitory response to the stop signal) is a component of both stop-signal and go/no-go tasks; however, the stop-signal task is specifically designed to evaluate the SSRT process by presenting stop signals close to the endpoint of the go response and monitoring the competition between stop and go processes in terms of which finishes first. The speed of processing of the stop signal does not affect the outcome of the go/no-go task

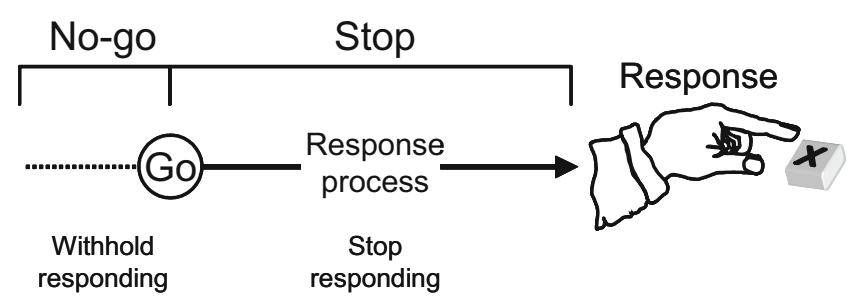

Fig. 1 Representation of the go/no-go and stop-signal tasks. In the stop-signal task, the stop signal is presented after the signal to go, so the response is in the process of completion. In the go/no-go task, the stop signal is presented before or contiguous with the go signal, so the subject must withhold a response 
because the evaluation of the stop-signal occurs well in advance of the go response at a point at which the race model predicts that inhibition should be $100 \%$ accurate. Often, evaluation of the stop and go signals occurs before the subject is allowed access to the lever/button on which to make the go response. Therefore, it is not possible to estimate SSRT from the go/no-go task (see Logan 1994 for the explanation of these theoretical issues).

The go/no-go task also contains a decision-making component that is absent from the stop-signal task, as a result of the relative positioning of the stop and go signals. In the stop-signal task, each trial starts off as a go-response trial, so there is no pre-response go or no-go selection. If a further signal occurs (the stop signal), the subject must change its response, but this is always an indicator of an inhibitory response, so no decision need be made. The stopsignal task is specifically designed to eliminate decisionmaking from the experimental process. In the go/no-go task, the subject must select a response strategy (to go or to inhibit) before initiating the response. Indeed, many go/nogo tasks present two stimuli (for rodents) or two sets of stimuli (for humans) that are very similar in nature (e.g. lights) as their go and no-go signals, potentially increasing the difficulty of the decision-making component of this task.

Schachar et al. (2007) noted that because the critical difference between stop-signal and go/no-go tasks is often the temporal location of the inhibitory signal within the main motor task (Fig. 1), it would be possible to devise a test procedure in which both action-restraint and actioncancellation components are presented within-session. Recently, within one basic task framework, the SSRT has been measured alongside stop-trial commission errors (measured under a condition when the go and stop signals were presented together, the no-delay or zero-delay condition) (e.g. Eagle and Robbins 2003a; Eagle et al. 2007; Rubia et al. 2001; Schachar et al. 2007). Examining action restraint and action cancellation in this way eliminates potentially confounding effects of comparing between different tasks and may provide a more practical framework for further analysing these forms of inhibition. In addition, this form of task reduces the decision-making component of the no-delay (go/no-go) form of the task: as in the stopsignal task, the correct response is always to go, unless the subject detects a stop signal. Whilst this procedure helps to eliminate the potential confounds on the go/no-go task of restraint and decision making, there may be separate issues associated with presentation of the stop and go signals at the same time (such as attentional conflicts), and clearly, there is scope for further task development to clarify these issues. For the purposes of this review, action restraint encompasses all 'no-go' responding (go/no-go and nodelay stop-signal tasks), evaluated as the presence or absence of response at a position in the go trial that allows all inhibitory responses to be completed once they are initiated. Action cancellation encompasses all studies in which the stop-signal is presented after the initiation of the go response and late enough to impair inhibition because the stop process did not finish in time. We hypothesise that because action restraint effectively measures whether action inhibition can be initiated and maintained and action cancellation evaluates specifically the time required for action inhibition to be implemented (SSRT), these forms of inhibition represent fundamentally different classes of inhibitory response that are anatomically and pharmacologically separable.

\section{Translational implications of response inhibition research}

Simple tests of behavioural inhibition, such as the go/no-go and stop-signal tasks that measure action restraint and action cancellation, respectively, are excellent tools for translational research as the basic forms of these tasks are appropriate for testing human, primate and rodent subjects without significant changes in experimental design. This permits the investigation of aspects of human psychiatric dysfunction using techniques that are simply not possible to use in studies with patients, for example, during the development of novel drug therapies. For both action restraint and action cancellation, rats and humans can perform almost identical versions of these tasks. This enables simultaneous study of pre-clinical and patient populations to establish the neural basis and experimental therapeutics of particular disorders. Of course, one must exercise caution when extrapolating across species from rats to humans with respect to cortical function, as homologies between regions of the human and rat cortex are controversial (Preuss 1995). However, we will argue that it is possible to use 'functional homology' (see Robbins 1998) to make tentative comparisons between structures that appear to modulate the same behavioural functions across the different species. Within the basal ganglia, however, structure has largely been conserved in evolutionary terms, making it far more credible to make direct comparisons between these species. This is also true to a major extent for the ascending neurotransmitter systems, e.g. noradrenaline, serotonin, dopamine and acetylcholine, although there are some important species differences (Bentivoglio and Morelli 2005; Lewis 2001; Mesulam et al. 1983; Robbins et al. 2006). With respect to both action restraint and action cancellation, it is becoming clear that the cross-species comparability is very strong and this review brings together, for the first time, evidence from many directly comparable studies across species. 


\section{Neural systems underlying action restraint and action cancellation}

Both action-restraint and action-cancellation impairments have been extensively documented as forms of frontostriatal dysfunction (Chamberlain and Sahakian 2007; Fuster 1988; Penades et al. 2007; Robbins 2007; Rubia et al. 2006a). Neuroanatomical studies of humans, non-human primates and rodents have pinpointed regions of the frontal cortex and basal ganglia that are critical for action inhibition, and interplay between these regions may be essential for attaining appropriate behavioural outcomes (Band and van Boxtel 1999). Early primate studies showed that lesions of the inferior convexity, a likely homologue in macaques of the right inferior frontal gyrus in humans, produced impairments in go/no-go performance (Iversen and Mishkin 1970), and in human studies, the go/no-go task has revealed actionrestraint deficits following frontal cortical damage (Decary and Richer 1995; Drewe 1975; Godefroy and Rousseaux 1996). Recent studies have highlighted several cortical regions of interest with respect to both stop-signal and go/ no-go tasks, in particular the inferior frontal cortex (IFC). For example, Aron et al. (2004) analysed the involvement of the dorsolateral prefrontal cortex (DLPFC), inferior frontal cortex (IFC) and dorsal anterior cingulate cortex (ACC) in behavioural inhibition tasks and concluded that the IFC and, in particular, the right IFC was critical to inhibition, whilst the other structures had more specific function in other processes within these tasks, such as maintaining the go response or generalised error monitoring.

Rubia et al. (2001) showed subtle differences between brain activation during go/no-go and stop-signal tasks in a comprehensive study using gradient-echo echoplanar MR imaging. Although selective inhibition in the stop-signal and go/no-go tasks activated a similar network of brain regions in both tasks, including IFC, ACC, pre-SMA (supplementary motor area), DLPFC and inferior parietal cortex (IPC), the pattern of activation tended to be bilateral for the go/no-go task and predominantly confined to the right hemisphere for the stop-signal task, a finding that is supported by a number of other studies (Aron et al. 2003b, 2004; Bunge et al. 2002; Garavan et al. 1999; Konishi et al. 1999; Konishi et al. 1998; Menon et al. 2001). For example, in the performance of the stop-signal task, patients with lesion damage to the frontal cortex displayed a strong correlation between lesion size within the right IFC and increased SSRT, whilst there was no such correlation between increased SSRT and lesion size to either the left hemisphere or to neighbouring regions to the right IFC within the right hemisphere (Aron et al. 2003b; Rubia et al. 2003).

In rats, the role of the prefrontal cortex in either actionrestraint or action-cancellation control is far from clear.
Although there are few studies in this area, the available evidence supports a role for the orbitofrontal cortex (OF) in both processes. There appears to be $\mathrm{OF}$ specificity for action cancellation because excitotoxic lesions of the OF, but not the anatomically adjacent infralimbic or prelimbic cortex, lengthened SSRT (Eagle et al. 2008; Eagle and Robbins 2003b). These effects were specific to SSRT as these lesions had no significant effect on the go response. Whilst direct homology between the right inferior frontal cortex in human subjects and the ventral orbitofrontal cortex in rats is unproven, these regions are currently the only cortical regions, in their respective subject species, to be specifically implicated in the control of SSRT.

There is conflicting evidence for a role for the $\mathrm{OF}$ in action restraint. NMDA-induced lesions of the lateral OF in rats did not impair acquisition of an odour-cued go/no-go task with subjects and control subjects able to perform nogo inhibitory responses (Schoenbaum et al. 2002). This evidence is supported by a lack of impairment following excitotoxic OF lesions in the no-delay condition in the stopsignal task (Eagle et al. 2008). Rats with OF lesions were, in fact, better at inhibiting responding in this 'no-go' condition, although they were impaired at stopping when the stop signal was presented during the go response (Eagle et al. 2008). This evidence contrasts with previous studies that found significantly impaired go/no-go performance following aspirative lesions of the OF (Eichenbaum et al. 1983; Eichenbaum et al. 1980), leading Schoenbaum et al. to conclude that OF damage was more disruptive to no-go performance if rats had pre-learned several series of discrimination tasks, but was ineffective in disrupting performance if task acquisition took place subsequent to the lesion surgery.

The basal ganglia are implicated in both action restraint and action cancellation. For example, adult patients with basal ganglia lesions have impaired action cancellation on a stop-signal task (Rieger et al. 2003) with a similar effect produced by excitotoxic lesions of the dorsomedial striatum in rats (Eagle and Robbins 2003a). In addition, SSRT deficits have been linked with abnormal subthalamic nucleus (STN) function in Parkinson's disease (Gauggel et al. 2004), and stimulation within the STN, but not surrounding structures, in these patients improved SSRT (van den Wildenberg et al. 2006). However, in the rat, lesions of the STN globally disrupted performance on the stop-signal task, both when the stop signal was delayed and when the stop signal was presented at the same time as the go signal, more strongly indicative of a generalised attentional or response selection (no-go-like) deficit following these lesions. This disruption of performance may have masked any effect of STN lesions on SSRT per se in the rat (Eagle et al. 2008). Subcortical function is often disrupted in ADHD during the processing of stop and no-go signals. 
For example, subjects with ADHD exhibited less striatal activation than control subjects during a go/no-go task, whilst there was no difference in cortical activation between groups (Vaidya et al. 1998).

Recent studies have begun to link the frontal cortex and basal ganglia evidence into a functional circuitry of action inhibition, but in particular relating to action cancellation. One candidate is a circuit connecting the orbital/inferior frontal cortex with striatum/caudate putamen (Chamberlain et al. 2006a; Eagle et al. 2008; Penades et al. 2007). In rats, there is subcortical specificity that suggests the existence of such discrete corticostriatal circuitry, at least with respect to action cancellation. Stop-signal task deficits can be induced by both OF lesions and lesions of the dorsomedial striatum (DMStr) (Eagle et al. 2008; Eagle and Robbins 2003a). The ventral OF projects mainly to the DMStr, but not to the core region of the nucleus accumbens (Groenewegen et al. 2005; Hoover and Vertes 2004; Schilman et al. 2007), lesions of which had no effect on SSRT (Eagle and Robbins 2003b).

The second candidate involves a role for the STN in the mediation of SSRT through a 'hyperdirect' connection with the inferior frontal cortex. This pathway could provide the rapid information processing required for action cancellation. In human subjects, STN activation correlated with decreased SSRTs (Aron and Poldrack 2006), and STN activation on the stop-signal task also correlated with activation of the RIFC. The relative merits of these pathways are still under investigation, but the ability to translate behavioural effects between species groups can only facilitate our understanding in this area.

\section{Role of serotonin (5-HT) in action inhibition}

Central serotonin function is widely acknowledged as an important mediator of behavioural inhibition and response control, and it has been proposed that decreased 5-HT contributes to increased impulsivity (Evenden 1999; Soubrie 1986). However, growing evidence, translating across rodent, primate and human studies, suggests that serotonin may be critical for only some of these behavioural subtypes of inhibition (Clark et al. 2005; Clarke et al. 2005; Dalley et al. 2002; Harrison et al. 1997; 1999; Mobini et al. 2000; Passetti et al. 2003; Winstanley et al. 2004a, b).

It is clear from studies of other forms of inhibition, both animal and human, that there are mixed effects of serotonin manipulations. For example, in rats, 5-HT depletion increased premature responding on the five-choice, and the modified one-choice, serial reaction time tasks, increased locomotor activity conditioned to food presentation and increased speed and number of responses made during autoshaping (Harrison et al. 1997; Winstanley et al. 2004a); all of which are well-recognised measures of altered impulse control. However, the effects of 5-HT depletion on impulsive choice (i.e. delayed gratification) were less clear with some studies finding increased impulsive choice with 5-HT depletion, and others finding no effects (Mobini et al. 2000; Winstanley et al. 2004a). In normal healthy human volunteers, using acute tryptophan depletion (ATD) to reduce 5-HT function produced mixed effects on inhibitory control (Crean et al. 2002; LeMarquand et al. 1999; Murphy et al. 2002; Riedel 2004; Rubinsztein et al. 2001; Walderhaug et al. 2002). Clark et al. (2005) hypothesised that the cognitive effects of 5-HT challenge may vary as a function of individual differences in ratings of impulsivity. Evidence for the role of 5-HT in stop-signal and go/no-go tasks is summarised in Table 1 and discussed below.

Role of 5-HT in action restraint

There is clear evidence that 5-HT plays a role in the modulation of action-restraint inhibition. In rats, global 5HT depletion following intra-cerebroventricular (i. c. v.) infusions of 5,7-DHT (5,7-dihydroxytryptamine) profoundly disrupted the acquisition of action restraint in response to a no-go signal and also impaired the ability of previously trained rats to subsequently inhibit correctly to a no-go signal (Harrison et al. 1999) with no change in other task measures. Similarly, rats administered parachloroamphetamine, to induce 5-HT depletion in the brain, showed impaired acquisition of a go/no-go task (Masaki et al. 2006).

Neuroimaging studies implicate the orbitofrontal cortex in relation to the effects of serotonin on action-restraint inhibition. For example, Rubia et al. (2005a) found that ATD decreased right orbito-inferior prefrontal activation in fMRI during the no-go condition, although there was no significant alteration in inhibitory performance on task. Citalopram enhanced the response of the lateral orbitofrontal cortex (BA47) to the no-go condition, whereas it attenuated the response to the no-go condition in the medial orbitofrontal (BA11), using fMRI (Del-Ben et al. 2005). In addition, fMRI investigation of healthy subjects' neural responses with or without the antidepressant mirtazapine, during performance of a go/no-go task, found significant activation in the right dorsolateral prefrontal cortex, right anterior cingulate, right temporal and right parietal cortex, left occipital cortex and left thalamus and bilateral middle frontal gyrus and orbitofrontal cortex, but of these, mirtazapine enhanced activation exclusively in the right lateral orbitofrontal cortex (Vollm et al. 2006). Anderson et al. (2002) showed an increased blood oxygen leveldependent (BOLD) signal in the right orbitofrontal cortex during go/no-go following treatment with a 5-HT2c agonist, $m$-chlorophenylpiperazine $(m \mathrm{CPP})$ in healthy adults. There is also evidence for a negative correlation between commission errors and 5-HT synthesis capacity in 
Table 1 Summary of the role of serotonin (5-HT), dopamine and noradrenaline in the stop-signal and go/no-go tasks showing the comparability of evidence between human and animal subjects

\begin{tabular}{|c|c|c|c|c|}
\hline Task & Experimental method & Effect & Notes (type or magnitude of effect) & References \\
\hline \multicolumn{5}{|c|}{ Serotonin $(5-\mathrm{HT})$} \\
\hline \multirow[t]{3}{*}{ SSRT human } & Citalopram (SSRI) & - & No effect on SSRT & Chamberlain et al. $2006 \mathrm{~b}$ \\
\hline & $\begin{array}{l}\text { Buspirone, partial serotonin } \\
\text { 1A receptor agonist }\end{array}$ & - & No effect on SSRT & Chamberlain et al. 2007 \\
\hline & Acute tryptophan depletion (ATD) & - & No effect on SSRT & Crean et al. 2002 \\
\hline \multirow[t]{2}{*}{ SSRT animal } & Serotonin transporter knockout mice & - & No effect on SSRT & Hausknecht et al. 2006 \\
\hline & $\begin{array}{l}\text { Global 5-HT depletion }(5,7- \\
\text { dihydroxytryptamine) in rats }\end{array}$ & - & $\begin{array}{l}\text { No effect on SSRT or any } \\
\text { other stop-task measure }\end{array}$ & $\begin{array}{l}\text { Eagle et al., unpublished } \\
\text { data }\end{array}$ \\
\hline \multirow[t]{6}{*}{$\begin{array}{l}\text { Go/no-go } \\
\text { human }\end{array}$} & $\begin{array}{l}\text { Acute tryptophan depletion } \\
\text { (ATD) fMRI }\end{array}$ & + & $\begin{array}{l}\text { No effect on no-go but decreased } \\
\text { activity in right orbito-inferior } \\
\text { prefrontal, superior and medial } \\
\text { temporal cortex during no-go }\end{array}$ & Rubia et al. 2005a \\
\hline & Citalopram (SSRI) fMRI & + & $\begin{array}{l}\text { Enhanced lateral orbitofrontal and } \\
\text { decreased medial orbitofrontal } \\
\text { response to no-go }\end{array}$ & Del-Ben et al. 2005 \\
\hline & Mirtazapine fMRI & + & $\begin{array}{l}\text { Enhanced right orbitofrontal } \\
\text { activity to no-go }\end{array}$ & Vollm et al. 2006 \\
\hline & $\begin{array}{l}m \text {-chlorophenylpiperazine ( } m \mathrm{CPP}) \\
5 \text {-HT(2c) agonist fMRI }\end{array}$ & + & $\begin{array}{l}\text { Enhanced activation in right lateral } \\
\text { orbitofrontal cortex during go/no-go }\end{array}$ & Anderson et al. 2002 \\
\hline & $\begin{array}{l}\text { alpha-[(11)C]MTrp trapping PET in men } \\
\text { with borderline personality disorder }\end{array}$ & + & $\begin{array}{l}\text { Lower alpha-[(11)C]MTrp trapping in } \\
\text { medial frontal gyrus, anterior cingulate } \\
\text { gyrus, superior temporal gyrus, and } \\
\text { striatum. Negative correlations with } \\
\text { no-go commission errors in the medial } \\
\text { frontal gyrus, anterior cingulate gyrus, } \\
\text { temporal gyrus, and striatum }\end{array}$ & Leyton et al. 2001 \\
\hline & $\begin{array}{l}\text { PET with }[(18) \text { F]altanserin to characterise } \\
\text { 5-HT(2) receptor binding }\end{array}$ & + & $\begin{array}{l}\text { A-1438A allele group made more no-go } \\
\text { errors than those in G- } 1438 \mathrm{G} \text { group }\end{array}$ & Nomura and Nomura 2006 \\
\hline \multirow[t]{2}{*}{$\begin{array}{l}\text { Go/no-go } \\
\text { animal }\end{array}$} & Global 5-HT depletion (5,7-DHT) in rats & + & $\begin{array}{l}\text { Unable to withhold responding and } \\
\text { thus correctly complete the no-go trials }\end{array}$ & Harrison et al. 1999 \\
\hline & Parachloroamphetamine (PCA) & + & Longer to acquire go/no-go & Masaki et al. 2006 \\
\hline \multicolumn{5}{|l|}{ Dopamine } \\
\hline \multirow[t]{3}{*}{ SSRT human } & L-DOPA dopamine agonist & - & No effect on SSRT or any other measure & Overtoom et al. 2003 \\
\hline & L-DOPA dopamine agonist & - & No effect on SSRT & $\begin{array}{l}\text { Clark et al., unpublished } \\
\text { data }\end{array}$ \\
\hline & $\begin{array}{l}\text { Seven-repeat allele of DRD4 in } \\
\text { children with ADHD }\end{array}$ & - & $\begin{array}{l}\text { No effect on percentage of inhibitions } \\
\text { but faster GoRT }\end{array}$ & Langley et al. 2004 \\
\hline SSRT Animal & cis-flupenthixol D1/D2 receptor antagonist & - & No effect on SSRT but slower GoRT & Eagle et al. 2007 \\
\hline \multirow[t]{4}{*}{$\begin{array}{l}\text { Go/no-go } \\
\text { human }\end{array}$} & $\begin{array}{l}\text { Acute phenylalanine tyrosine depletion } \\
\text { (APTD) }+ \text { L-DOPA }\end{array}$ & $-1+$ & $\begin{array}{l}\text { In rewarded condition, APTD increased } \\
\text { commission errors on go/no-go and } \\
\text { L-DOPA restored baseline levels. In loss } \\
\text { condition, APTD and L-DOPA had no } \\
\text { significant effects }\end{array}$ & Leyton et al. 2007 \\
\hline & $\begin{array}{l}\text { Seven-repeat allele of DRD4 in } \\
\text { children with ADHD }\end{array}$ & - & $\begin{array}{l}\text { No effect on percentage of inhibitions } \\
\text { but faster GoRT }\end{array}$ & Langley et al. 2004 \\
\hline & APTD & - & $\begin{array}{l}\text { No effect on no-go false alarms in either } \\
\text { affective or non-affective go/no-go. } \\
\text { Faster response times in both }\end{array}$ & $\begin{array}{l}\text { Vrshek-Schallhorn } \\
\text { et al. } 2006\end{array}$ \\
\hline & L-DOPA fMRI & $-/+$ & $\begin{array}{l}\text { Pre-L-DOPA activity in the right parietal } \\
\text { cortex correlated with false-alarm rate, } \\
\text { but no significant effect of 1-DOPA on } \\
\text { overall false-alarm rate }\end{array}$ & Hershey et al. 2004 \\
\hline
\end{tabular}


Table 1 (continued)

\begin{tabular}{|c|c|c|c|c|}
\hline Task & Experimental method & Effect & Notes (type or magnitude of effect) & References \\
\hline \multirow[t]{2}{*}{$\begin{array}{l}\text { Go/no-go } \\
\text { animal }\end{array}$} & $\begin{array}{l}\text { D1 and D2 dopamine receptor agonists } \\
\text { (SKF38393, quinpirole) and antagonists } \\
\text { (SCH23390, sulpiride) }\end{array}$ & - & $\begin{array}{l}\text { No difference in D1-and D2-drug effects } \\
\text { on neuronal activity between go and } \\
\text { no-go trials }\end{array}$ & Inase et al. 1997 \\
\hline & cis-flupenthixol D1/D2 receptor antagonist & - & $\begin{array}{l}\text { No effect on no-delay percentage of } \\
\text { inhibition (using stop-task format) }\end{array}$ & Eagle et al. 2007 \\
\hline \multicolumn{5}{|l|}{ Noradrenaline } \\
\hline \multirow[t]{3}{*}{ SSRT human } & Atomoxetine SNRI & + & SSRT improved & Chamberlain et al. $2006 \mathrm{~b}$ \\
\hline & Desipramine & + & SSRT improved & Overtoom et al. 2003 \\
\hline & Guanfacine $\alpha 2 \mathrm{~A}$ receptor agonist & - & No effect & Muller et al. 2005 \\
\hline \multirow[t]{2}{*}{ SSRT animal } & Atomoxetine (NARI) & + & SSRT improved & Robinson et al. 2008 \\
\hline & Guanfacine $\alpha 2 \mathrm{~A}$ receptor agonist & - & No effect & $\begin{array}{l}\text { Bari et al., unpublished } \\
\text { findings }\end{array}$ \\
\hline $\begin{array}{l}\text { Go/no-go } \\
\text { human }\end{array}$ & & $*$ & & \\
\hline \multirow[t]{2}{*}{$\begin{array}{l}\text { Go/no-go } \\
\text { animal }\end{array}$} & $\begin{array}{l}\text { Clonidine (alpha-2 receptor agonist) and } \\
\text { B-HT920 (agonist for alpha-2 and D2 } \\
\text { receptors) examined iontophoretically on } \\
\text { neurons in the prefrontal cortex of monkeys }\end{array}$ & + & $\begin{array}{l}\text { Enhancement of neuronal activity } \\
\text { related to both go and no-go } \\
\text { performance. Blocked by yohimbine } \\
\text { but not sulpiride (D2) suggesting } \\
\text { alpha-2 receptor involvement }\end{array}$ & Li and Kubota 1998 \\
\hline & Yohimbine infusion into prefrontal cortex & + & $\begin{array}{l}\text { No-go performance impaired } \\
\text { selectively }\end{array}$ & Ma et al. 2003 \\
\hline
\end{tabular}

+ indicates effect, - indicates no effect, $*$ indicates no known studies

some cortical sites, including the medial frontal gyrus (Leyton et al. 2001).

Although this evidence pinpoints the orbitofrontal cortex as a key locus for the action of serotonin during actionrestraint inhibition, the precise mechanism by which serotonin exerts its influence over performance via the orbitofrontal cortex is far from clear. Recently, it has been proposed that a polymorphism in the promoter of the 5HT2A receptor gene may underlie some forms of behavioural inhibition, and there is evidence of a role for this receptor in action-restraint inhibition. Subjects with the A-1438A allele of the 5-HT(2A) receptor gene made more commission errors under the punishment-reward condition in a go/no-go task than those in the G-1438G group (Nomura and Nomura 2006). The role of other 5-HT receptor subtypes in action restraint is not known.

\section{Role of 5-HT in action cancellation}

In contrast to the strong evidence supporting a role for 5$\mathrm{HT}$ in action restraint, there is no evidence that 5-HT plays any significant role in the modulation of action cancellation. Clark et al. (2005) found that depletion of brain serotonin had no effect on SSRT, even when subjects were stratified according to 5-HT transporter polymorphism. Neither the partial serotonin 1A receptor agonist, buspirone, nor the selective serotonin reuptake inhibitor, citalopram, had any effects on SSRT in healthy volunteers (Chamberlain et al. 2006b, 2007), and the lack of effect of citalopram on SSRT has recently been replicated in rats (Fig. 2). Furthermore, in rat studies, global (i. c. v.) 5,7-DHT lesions had no effect on SSRT or any other primary measure on the stop-signal task (Eagle et al., unpublished data), and serotonin transporter knockout mice showed no differences in any baseline measure on the stop-signal task from wild type controls (Hausknecht et al. 2006). There is also no clinical evidence to support the use of serotonin-based drugs in the treatment of the core impulsive motor symptoms of ADHD.

Indirect support for a lack of effect of serotonin in the mediation of action cancellation comes from a study by van den Bergh et al. (2006) who found no link in rats between aggression towards intruders and slowing of SSRT, although they did find a direct correlation between this form of aggression and another form of behavioural disinhibition, impulsive choice (delayed gratification). This indirectly supports the lack of effect of serotonin in the control of stopping because there are links between serotonin and some, although not all, forms of aggression. For example, serotonin depletion using ATD may increase aggression in subjective assessment and in laboratory tests such as the Point Subtraction Aggression Paradigm and Taylor Competitive Reaction Time Task (Bjork et al. 1999, 2000; Cleare and Bond 1995; Moeller et al. 1996; Pihl et al. 1995; Salomon et al. 1994).

Only one study (Crean et al. 2002) shows a weak link between serotonin and action cancellation. They found that although there was no statistically significant effect of dietary tryptophan depletion on action cancellation (SSRT) 

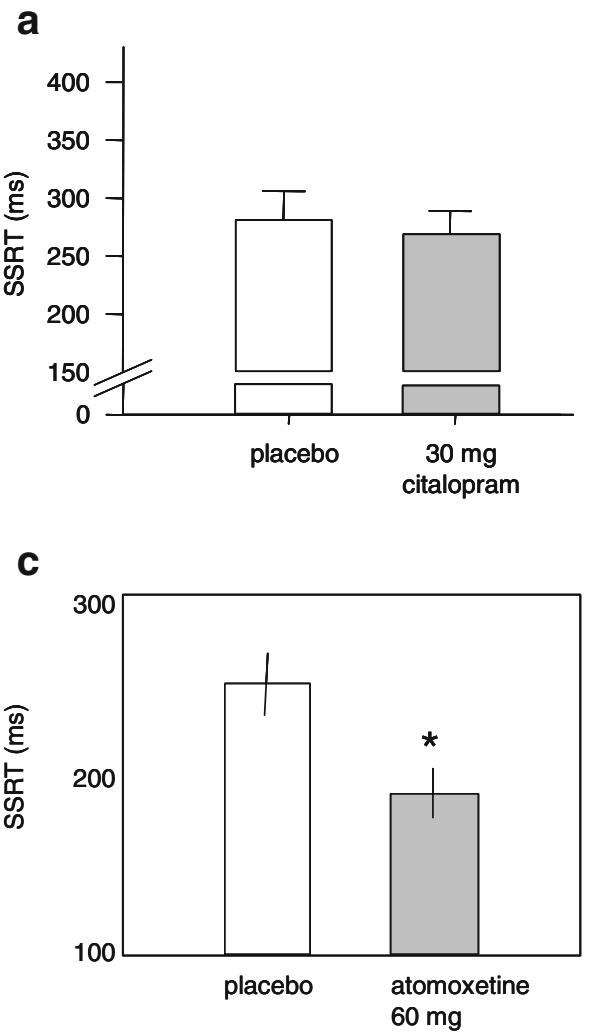

e

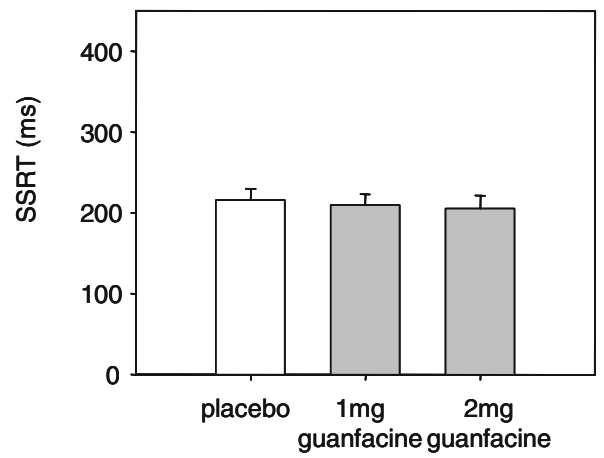

Fig. 2 a and $\mathbf{b}$ The lack of effect of citalopram on SSRT in a human and $\mathbf{b}$ rat subjects (Bari et al., unpublished findings). a No effect on SSRT of orally administered citalopram in a between-subjects $(n=20)$ treatment $(p \leq 0.973)$. b No effect on SSRT of intraperitoneally administered citalopram in a within-subjects $(n=26)$ treatment (dose $F(4,100)=0.23$, n.s.). Methodology in $\mathbf{b}$ was identical to that described in Eagle et al. (2007) with drugs administered following a randomised Latin square design. $\mathbf{c}$ and $\mathbf{d}$ Significant effects of atomoxetine on SSRT in $\mathbf{c}$ human and $\mathbf{d}$ rat subjects. $\mathbf{c}$ Significant effect of orally administered atomoxetine in a between-subjects $(n=20)$ treatment $(p \leq$ 0.014). d Significant effect of intraperitoneally administered atomoxetine in a within-subjects $(n=11)$ treatment $(p \leq 0.002)$. e and

in healthy volunteers with no family history of alcoholism following tryptophan depletion, their SSRTs were significantly faster than a group that had a family history positive for alcoholism. There may, therefore, be some effect of 5-HT depletion in populations with different baseline levels of impulsivity, and this hypothesis merits further investigation.
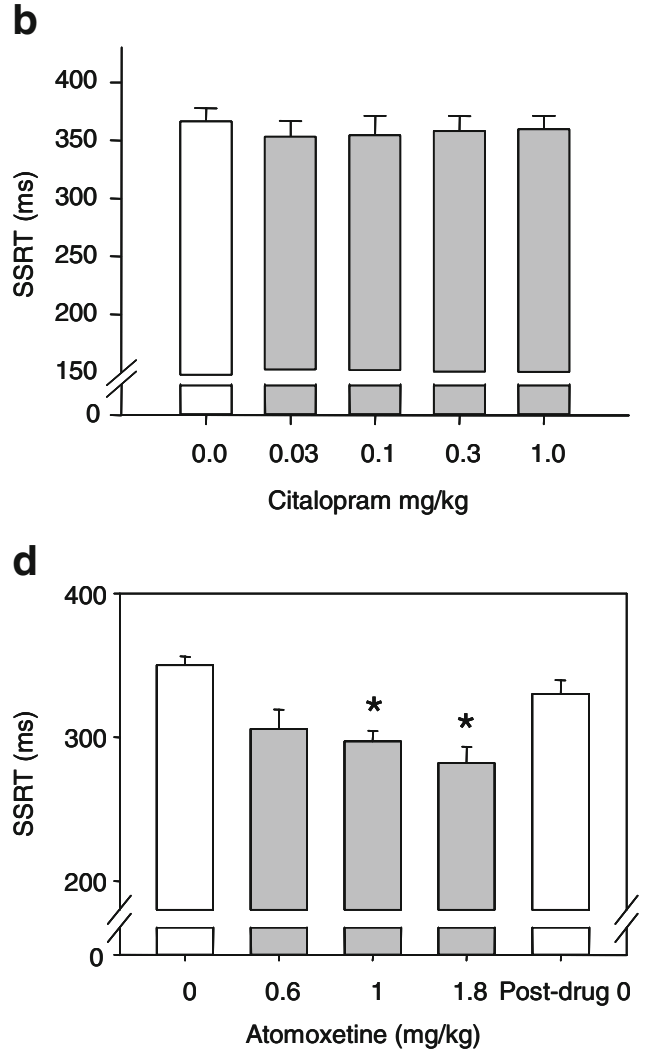

f

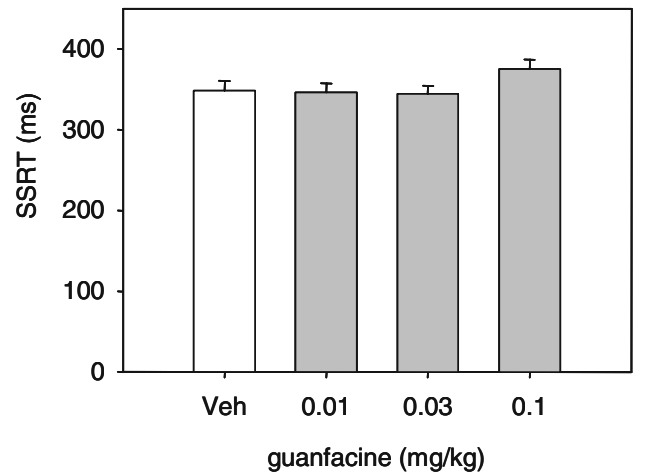

$\mathbf{f}$ The lack of effect of guanfacine on SSRT in e human and $\mathbf{f}$ rat subjects (Bari et al., unpublished findings). e No effect on SSRT of orally administered guanfacine in a between-subjects $(n=20)$ treatment $(F(2,55)=0.124$, n.s. $)$. f No effect on SSRT of intraperitoneally administered guanfacine in a within-subjects $(n=22)$ treatment (dose $F(3,63)=1.78$, n.s.). Methodology as for b. Asterisk indicates significant difference from vehicle. a with permission and adapted from Chamberlain et al. 2006a, b. c with permission and adapted from Chamberlain et al. 2006a, b. d with permission and adapted from Robinson et al. (2008). e with permission and adapted from Muller et al. 2005

Clark et al. (2005) commented that the actions of 5-HT in response inhibition might be critical to stop-signal task performance only if "trial-by-trial performance was associated with motivational consequences in terms of either reinforcement or punishment" because many behaviours known to be modulated by 5 -HT contain a component of 
reward/punishment-related feedback. In the human stopsignal task, there is usually no formal form of reinforcement for correct trials. However, in the rat version of this task where performance was maintained using food reinforcement, there was still no effect of 5-HT depletion on performance (Eagle et al., unpublished data). Therefore, it appears that the lack of effect of 5-HT depletion in the human study may not result from the lack of reinforcement on the task. It is probable that global disruption of the 5-HT system in healthy subjects does not, in fact, influence the action-cancellation form of action inhibition.

The role of serotonin in action inhibition: a summary

Serotonin clearly influences action restraint but not action cancellation. Whilst serotonin does not influence SSRT, it may influence any one of several behavioural components in the go/no-go task, such as the discrimination of go and nogo signals, decision making, or withholding responding. Serotonin manipulations appear to be specific to the initiation or maintenance of inhibition, rather than discrimination or selection of the go and no-go signals or the processing of errors/feedback because 5-HT-depleted rats have unimpaired acquisition of conditional visual discriminations where both of the correct choices involve active responses (Graham et al. 1994; Ward et al. 1999). Harrison et al. (1999) suggested that the deficit following global 5-HT depletion in rats was the inability to withhold responding following inhibition. This is further supported by evidence that 5-HT receptor manipulations affect premature responding (decrease the ability to withhold) on the five-choice serial reaction time task (Koskinen et al. 2000; Ruotsalainen et al. 1997), whereas there is no evidence that 5-HT manipulations affect response selection or attention on that task (Harrison et al. 1997; Robbins 2002). In fact, in the no-delay version of the stop-signal task, rats with global serotonin depletion are also unable to withhold inhibition in an extended limited hold challenge (Eagle et al., unpublished data).

\section{Psychostimulant effects on action inhibition: the role of catecholamines}

Dopamine and noradrenaline are clearly implicated in processes of behavioural inhibition. (Arnsten 2006; Arnsten and $\mathrm{Li}$ 2005; Cardinal 2006; Cardinal et al. 2004; Chamberlain and Sahakian 2007; Dalley et al. 2004; Davids et al. 2003; Evenden and Ryan 1996; Robbins 2002; Robbins and Everitt 1987; Winstanley et al. 2006). However, to a large degree, our knowledge of catecholaminergic mediation of action inhibition has come from studying the action of psychostimulants, which act in general as indirect catecholamine agonists. By blocking DA reuptake and promoting the release of DA from axon terminals (Axelrod et al. 1970; Hendley et al. 1972; Ross 1978), the subsequent increase in DA, mainly in the striatum, may underlie the therapeutic effects of these drugs.

Psychostimulants such as methylphenidate (Ritalin ${ }^{\mathrm{TM}}$ ), the most commonly prescribed drug in the treatment of ADHD, and D-amphetamine have proven modulatory effects on both action restraint and action cancellation (Aron et al. 2003a; Bedard et al. 2003; Paule et al. 2000; Solanto 1986, 1998; Spencer et al. 2001; Tannock et al. 1989; Vaidya et al. 2005). For example, methylphenidate (MPH) decreases SSRT in both adult and childhood ADHD (Aron et al. 2003a; Bedard et al. 2003; Tannock et al. 1989) and reduces commission errors in both ADHD and control subjects on go/no-go (Vaidya et al. 1998). This fMRI study by Vaidya et al. 1998 clearly shows the subcortical effects of MPH that could mediate its action-inhibition effects: control-group children had high caudate and putamen activity that was significantly reduced by MPH (Vaidya et al. 1998), whereas children with ADHD had lower baseline caudate and putamen activity that significantly increased following treatment with MPH. This may reflect differences in baseline dopamine activity, as PET imaging of MPH effects in healthy adults showed that changes in brain metabolism varied as a function of dopamine receptor availability (Volkow et al. 1997), and fits with findings that methylphenidate increases extracellular striatal DA (Volkow et al. 2001). However, behaviourally, methylphenidate had similar effects in both the control and ADHD groups, reducing commission errors during no-go trials in both groups (Vaidya et al. 1998). MPH-related striatal activation has been reported in ADHD subjects in several other studies (Lou et al. 1989; Rosa-Neto et al. 2005).

Recently, an atypical stimulant, modafinil (diphenylmethyl-sulphinyl-2-acetamide), has gained significant interest as a potential treatment of ADHD. Modafinil improved symptoms in both childhood ADHD (Rugino and Copley 2001; Rugino and Samsock 2003) and adult ADHD (Taylor and Russo 2000; Turner et al. 2004) and decreased SSRT in healthy adults (Turner et al. 2003). Modafinil is of particular interest to this review as its effects appear to be highly specific to action cancellation. Modafinil has no effects on either the go process (GoRT) or the no-delay, action-restraint component of the stopsignal task (Eagle et al. 2007; Turner et al. 2004), unlike conventional psychostimulants which often speed GoRT and SSRT (Bedard et al. 2003; Lijffijt et al. 2006; Tannock et al. 1989). From a translational perspective, modafinil similarly improves SSRT in rats and humans (Eagle et al. 2007; Turner 2006; Turner et al. 2003, 2004), effects that are directly comparable with the effects of conventional psychostimulants. 
Modafinil is conventionally used to treat narcolepsy and idiopathic hypersomnia by stimulating wakefulness and vigilance (Bastuji and Jouvet 1988; Billiard et al. 1994), leading to suggestions that the therapeutic benefits conferred to ADHD sufferers resulted from generally improved vigilance and attention. This has yet to be supported by controlled studies in experimental animals; for example, Waters et al. (2005) found no improvement in rat performance with modafinil on the five-choice serial reaction time test, a well-documented test of attentional control (Robbins 2002). However, the evidence for a specific SSRT-improving role for modafinil suggests that it may also confer non-attentional benefits because the stopsignal task measures a process with relatively low attentional demands, given the salience of the stop signal.

Evidence for baseline dependence of psychostimulant action

The apparently paradoxical efficacy of stimulant drugs to ameliorate the hyperactive or impulsive symptoms of ADHD may result from baseline dependence of some of the drugs' effects on action inhibition. This hypothesis is supported by studies of both action restraint and action cancellation. For example, D-amphetamine decreased 'false alarms' in go/no-go performance in humans (de Wit et al. 2002) with a greater improvement (reduction) in false-alarm rate for subjects with the worst initial performance. These were also the subjects who reported experiencing the lowest levels of amphetamine-induced euphoria, supporting the hypothesis that this drug acts differently upon sub-groups of a normal population. Such baseline-dependent effects of drugs are also found for action cancellation and translate well between rat and human studies (Fig. 3). In both humans and rodents, Damphetamine decreased SSRT only when subjects had relatively slow baseline SSRT (de Wit et al. 2000; Feola et al. 2000). Similar effects can be seen for methylphenidate (Boonstra et al. 2005; Eagle et al. 2007), and modafinil in both human and rat (Eagle et al. 2007; Turner personal communication). Baseline-dependent psychostimulant action was also found in a rodent study within which the SSRT was artificially manipulated (rather than the natural within-population variability considered above). Rats with dorsomedial striatal lesions with impaired SSRTs compared with control subjects had significantly improved SSRTs following D-amphetamine treatment, whereas control subjects showed little response to the drug (Eagle and Robbins 2003a). Indeed, studies that have found little effect of stimulant drugs on SSRT have usually only considered the population as a whole (Fillmore et al. 2005). The clear benefit of using normal variation within a population to investigate disorders such as ADHD is that symptoms of these disorders can be modelled whilst making no assumptions about their underlying pathology, unlike other potential 'models' of ADHD.

Such baseline dependence may in part explain the relatively high frequency of ADHD subjects that are unresponsive to either methylphenidate or D-amphetamine. In up to $30 \%$ of ADHD cases, methylphenidate fails to improve or even worsens symptoms such as deficient action inhibition (Cantwell 1996; Krause et al. 2005), perhaps because MPH only improves deficient action inhibition in the cases that have the most pronounced action-inhibition deficits. One hypothesis is that the effectiveness of methylphenidate treatment of ADHD symptoms is correlated with DAT availability in the striatum (Krause et al. 2005), although the direct relationship between DAT availability and either action-restraint or action-cancellation forms of inhibition is unclear. It would be interesting to investigate this hypothesis further.

In summary, whilst the study of psychostimulants has improved our understanding of the pharmacological basis of both action restraint and action cancellation, the relative contributions of dopamine and noradrenaline to these processes are still far from clear. The following sections review the current evidence for specific catecholaminergic modulation of action inhibition (summary in Table 1), which is of increasing relevance as interest turns towards treating conditions such as ADHD with non-stimulant, receptor-specific drugs.

\section{Candidate transmitter systems for psychostimulant action}

As well as a clear role for dopamine, psychostimulants may also interact with noradrenaline (NA) (Kuczenski and Segal 1997), which has also been implicated in the modulation of prefrontal cortical function (e.g. Arnsten and Dudley 2005) and 5-HT (Gainetdinov et al. 1999). Thus, the effects of psychostimulants on action restraint and action cancellation may be mediated by DA, NA, 5-HT or any combination, and it is unclear exactly how psychostimulants affect catecholaminergic mechanisms to modulate either RIFG or striatal action during action inhibition. de Wit et al. 2002 presciently stated that "the abuse potential of D-amphetamine is probably related primarily to its effects at the dopamine receptor (e.g. Wise and Bozarth 1987), but it is less clear if the effects of this drug on impulsive behaviour are mediated by DA as well'.

Action cancellation

Serotonergic mediation of psychostimulant action may be critical to some forms of inhibitory deficit, for example, serotonin-increasing agents exert the same paradoxical 
Fig. 3 Baseline-dependent effects of psychostimulants on SSRT translate between human and rat subjects. Effects of Damphetamine on SSRT in a rat and $\mathbf{b}$ healthy human subjects. Effects of methylphenidate on SSRT in $\mathbf{c}$ rats and $\mathbf{d}$ human adults with ADHD. Effects of modafinil on SSRT in e rats and f human adults with ADHD. Asterisk represents significant difference from vehicle or placebo. a with permission and adapted from deWit et al. 2000. b with permission and adapted from Feola et al. 2000. c with permission and adapted from Eagle et al. 2007. d Data within Boonstra et al. 2005. e with permission and adapted from Eagle et al. 2007. f Data within Turner et al. 2004
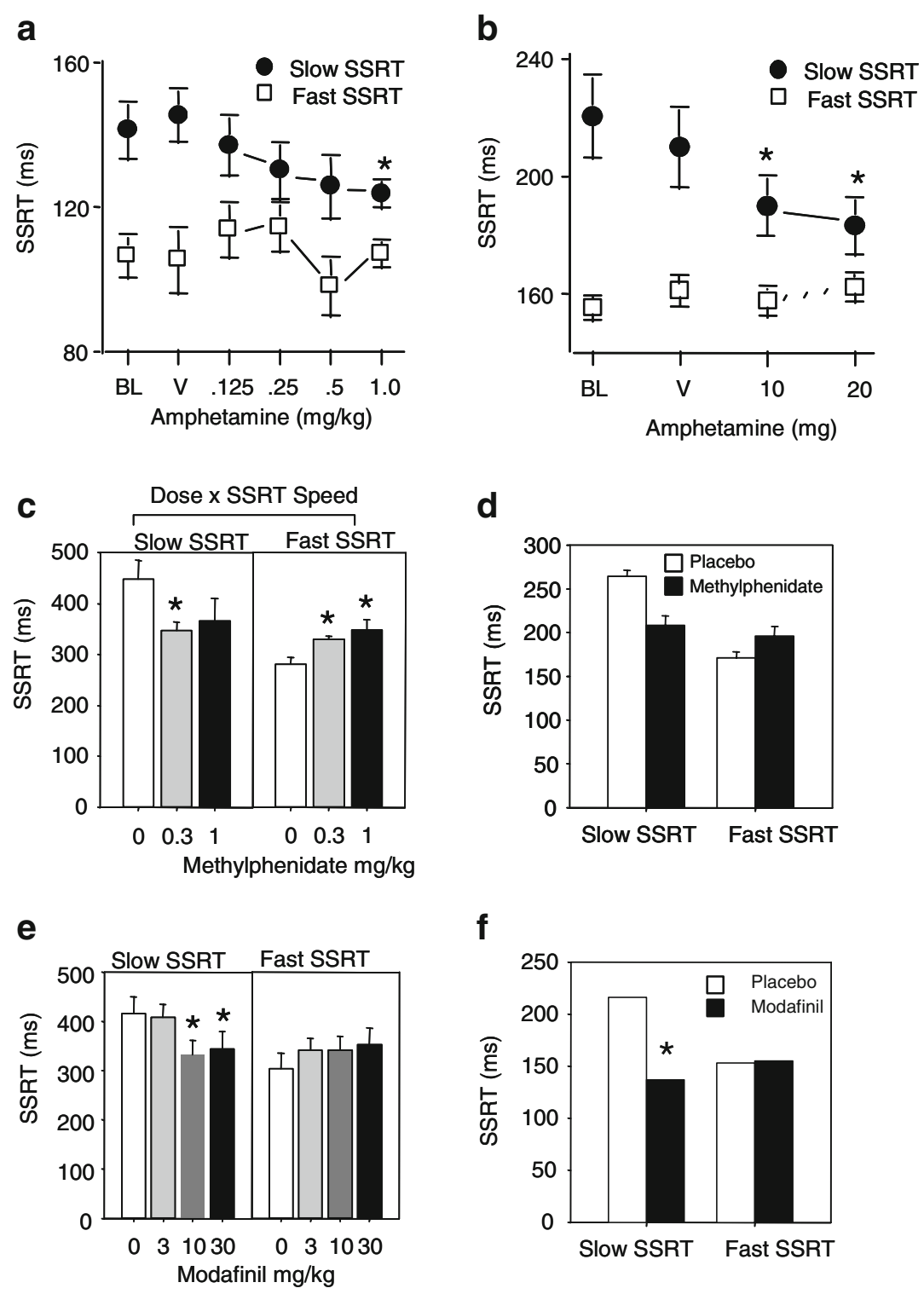

calming effects as psychostimulants in DAT-KO mice (Gainetdinov et al. 1999). However, given the lack of effect of 5-HT on SSRT, it is unlikely that the SSRT-improving effects of psychostimulants are via 5-HT receptors.

Similarly, although dopaminergic drugs can clearly increase impulsive behaviour on other tasks, e.g. delayed reward (Wade et al. 2000), such drugs have little effect on action cancellation or SSRT. Overtoom et al. (2003) found no effect of L-DOPA on SSRT (findings that have been repeated by Clark et al., unpublished data). Although Fillmore and colleagues reported that cocaine users had impaired SSRTs compared with non-cocaine-using control subjects, suggesting possible dopaminergic involvement in action cancellation, it was not possible to determine whether these differences already existed or resulted from the cocaine use (Fillmore and Rush 2002; Fillmore et al. 2002).
The mixed D1/D2 receptor antagonist, cis-flupenthixol, had no effect on action cancellation, but perhaps more critically, it did not influence the SSRT-decreasing effects of methylphenidate and modafinil at doses that significantly increased the GoRT (Eagle et al. 2007). This is perhaps the most convincing evidence to date that D1 and D2 receptors play little role in the mediation of SSRT. Whilst it is possible that methylphenidate or D-amphetamine might act via other DA receptors, there is no clear evidence to support a dopaminergic mechanism of action cancellation with respect to SSRT. Although polymorphisms in the DA receptor D4 (DRD4) gene in ADHD are thought to be critical for cognitive function in some respects, a comparison of ADHD children with or without at least one DRD4 seven-repeat allele found no difference in action cancellation, although there was a difference in GoRTs (Langley et 
al. 2004), a finding reinforced by a study by Rubia et al. (2006b) showing that the presence of the DRD4 repeat allele was related to poor inhibitory capacity in the go/no-go but not the stop-signal task. Altogether, the evidence, at present, is against a direct role for DA in action cancellation.

There is growing evidence in support of noradrenergic control of action cancellation. The selective noradrenaline reuptake inhibitor atomoxetine decreased SSRT in healthy adults (Fig. 2) with no effect on GoRT (Chamberlain et al. 2006b). This effect has recently been repeated with rats with SSRT-specific improvements following treatment with atomoxetine, but no significant change in GoRT (Robinson et al. 2008). Overtoom et al. (2003) found that desipramine also improved SSRT without affecting GoRT. Clearly, these studies provide the best evidence to date that a specific neurotransmitter, noradrenaline, is important for action cancellation, and the clear translational effect of atomoxetine on SSRT can be compared directly with the clear translational lack of effect of citalopram on the same measure (Fig. 2). In addition, the SSRT-improving specificity of noradrenergic manipulations is so similar to the pattern of effects of modafinil on this task that it would not be unreasonable to suggest that modafinil also improves SSRT via noradrenaline action. Whilst modafinil exhibits effects on catecholamines, serotonin, glutamate, gamma amino-butyric acid, orexin and histamine systems in the brain (Minzenberg and Carter 2008), the evidence reviewed in this paper suggests that it exerts its action over SSRT via noradrenaline. However, the effects of noradrenaline and, thus, the possible effects of modafinil on action cancellation may not be modulated via the $\alpha 2 a$-adrenergic receptor specifically because guanfacine had no effect on SSRT in healthy adults (Muller et al. 2005) or in rats (Bari et al., unpublished findings; Fig. 2). It should, however, be noted that atomoxetine does influence DA release in the rat prefrontal cortex (Bymaster et al. 2002), pinpointing the need for further studies in this area.

\section{Action restraint}

Frank and colleagues suggest that dopamine dynamically modulates the balance of go and no-go basal ganglia pathways during cognitive learning and performance (Frank and O'Reilly 2006; Frank et al. 2006). However, the effects they define as increased inhibition may be construed as a negative modulation of the go pathway rather than positive modulation of the no-go pathway, and there is little evidence to support a role for either D1 or D2 receptors in no-go inhibition. Inase et al. (1997) investigated the effect of D1 and D2 receptor agonists SKF38393 and quinpirole and antagonists $\mathrm{SCH} 23390$ and sulpiride on single-unit activity in the putamen of monkeys performing a go/no-go task. They showed that both D1 and D2 receptor agents could modulate the activity of neurons in both go and no-go trials but found no selective difference between go and no-go trials in the effectiveness of D1 or D2 manipulations. In rats, the mixed D1/D2 antagonist, cisflupenthixol, had no significant effect on no-delay (no-go) stop-trial accuracy (unpublished data from Eagle et al. 2007: comparison of no-delay stop-trial accuracy for vehicle, 0.01 and $0.04 \mathrm{mg} / \mathrm{kg}$ cis-flupenthixol; $F(2,36)=$ 2. 38 , n.s.), which again fails to support a role for D1 and D2 receptors in no-go inhibition. However, the highest of these doses of $c i s$-flupenthixol clearly slowed the go response, suggesting that D1/D2 receptors are more strongly implicated in the regulation of the go response than in any aspect of action inhibition. One possible candidate in the control of action restraint is the D4 receptor because the presence of the DRD4 repeat allele was related to poor inhibitory capacity in the go/no-go task (Rubia et al. 2006b).

Any studies that find effects of non-stimulant dopamine manipulations on action restraint appear to be highly dependent on the reinforcement outcome of no-go trials. For example, acute phenylalanine/tyrosine depletion (APTD) increased commission errors on a go/no-go task (Leyton et al. 2007), a deficit that was reversed by treatment with L-DOPA. However, this was only the case for trials in which a correct no-go response was rewarded: neither APTD nor 1-DOPA affected no-go trials during which a correct inhibition instead prevented punishment. Other studies, which gave no trial-by-trial reinforcement, failed to find either an effect of APTD (Vrshek-Schallhorn et al. 2006) or L-DOPA (Hershey et al. 2004) on no-go errors.

There are few studies that directly address the role of noradrenaline in action restraint, but those that do implicate alpha-2 adrenoceptors. Neurons that responded specifically to the no-go signal, but not the go or waiting signals, displayed increased activity in response to a mixed alpha-2/ D2 agonist, B-HT920, and this increase in activity was blocked by the alpha- 2 antagonist yohimbine, but not the D2 antagonist sulpiride (Li and Kubota 1998). Further work showed that infusion of yohimbine directly into the prefrontal cortex of macaques selectively impaired inhibition following a no-go signal (Ma et al. 2003).

\section{Summary}

This review has assessed the anatomical and pharmacological evidence relating to the modulation of two apparently similar forms of inhibition, action restraint, as measured in go/no-go tasks, and action cancellation, as measured in stop-signal tasks. Whilst there is a degree of overlap in the neural circuitry involved in controlling both types of inhibition, there are clear 
and critical neuropharmacological differences between action restraint and action cancellation. This is particularly the case with respect to the involvement of 5-HT, which is implicated in action restraint but not significantly in action cancellation. Perhaps most surprisingly, there is no clear evidence to support a role for dopamine in action cancellation with even the role of dopamine in action restraint being very unclear, although it does have very strong associations with the go response. Instead, growing evidence supports noradrenaline as a candidate neurotransmitter in the mediation of the actioncancellation form of inhibition.

Of particular interest, though, is the excellent translation of effects between species, in terms of basic behavioural findings, neuroanatomical substrates and response to drug/ neurochemical manipulations of the dopaminergic, noradrenergic or serotonergic systems. Especially striking are the effects of psychomotor-stimulant drugs such as methylphenidate or modafinil which appear to have broadly similar qualitative effects in humans and experimental animals. The demonstration of baseline-dependent effects in both species for psychostimulant-induced improvements in SSRT is of evident translational relevance for the treatment of such neuropsychiatric disorders as ADHD, the inhibitory deficits of which are commonly assessed using go/no-go or stopsignal tasks such as those reviewed in this paper.

Acknowledgements This study was supported by a Wellcome Trust Programme Grant (076274/z/04/z) awarded to TWR, B.J. Everitt, B.J. Sahakian and A.C. Roberts and completed within the University of Cambridge Behavioural and Clinical Neuroscience Institute, supported by a joint award from the Medical Research Council and the Wellcome Trust). A. Bari received financial support from Pfizer Inc. The authors acknowledge advice from A. Schmidt. TWR discloses consultancy for Cambridge Cognition and Eli Lilly as well as a research grant from Pfizer Inc.

\section{Appendix}

The stop-signal reaction time task (adapted from Logan 1994 and Eagle and Robbins 2003a).

The stop-signal reaction time task (SSRT) task assesses the time required to stop a response that is already in the process of being executed. The key measure on this task, SSRT (the time taken, after a stop signal is presented, for inhibition to be completed) cannot be measured directly as there is no observable endpoint to the response inhibition. Logan and Cowan (1984) presented a method of estimating the finishing point of the stop process, which proposes that the 'stop' and 'go' processes are independent of one another, that a 'race' occurs between the two processes for completion, and that whichever process finishes first wins the race. If the go process wins, a response occurs, and if the stop process wins, a response is inhibited. The finishing times of these processes are assumed to vary randomly, so the outcome of the race is a matter of probability. The race model assumes the stop process to be faster than the go process, and the placement of the stop signal during the go process biases the race in favour of one process or the other. For example, if the stop signal occurs early in the trial, the response will usually be inhibited (Fig. a). Conversely, if the stop signal occurs late enough, the response will rarely be inhibited (Fig. b). An inhibition function can be generated between these two extremes by plotting the probability of inhibition against stop-signal delay (SSD; Fig. c). An estimate of SSRT is calculated from the inhibition function and distribution of go-trial reaction times (GoRT). In general, lower, flatter inhibition functions indicate deficits in inhibitory control.

In order for the race model to be applicable, subjects must attempt to perform go trials as quickly as possible, while attempting to stop on all trials in which they detect a stop signal. The 'race' model fails if subjects slow their response on go trials to anticipate presentation of the stop signal. In the rat task, response speed on go trials is encouraged by restricting the trial length (limited hold; $\mathrm{LH})$, resulting in an incorrect response if subjects are too slow. In the human task, subjects receive verbal instructions about maintaining response speed, but some tasks also include a LH to prevent response slowing.

Subjects must also attempt to stop on all stop trials. Failure to trigger the inhibition process on a constant proportion of trials, regardless of the position of the stop signal produces lower inhibition functions that may result in inflated estimates of SSRT.

This task provides an estimate of the time taken to stop a response (SSRT) from measurable task parameters, the gotrial reaction time distribution, and the accuracy of stopping on stop trials (Figs. a-c). The GoRT provides a measure of the speed of the go process.

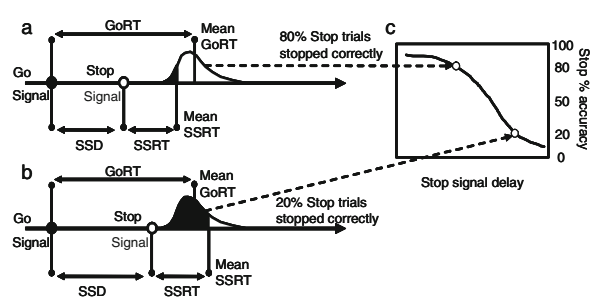

Estimation of stop-signal reaction time.

SSRT can be estimated using the protocol described in Logan (1994). Reaction times on go trials (on which no stop signal occurred) are rank ordered. The $n$th RT is selected from the ranked list of GoRTs for a particular delay session, where $n$ is obtained by multiplying the number of RTs in the distribution by the probability of responding on 
stop trials in the same session. This is an estimate of the time at which the stopping process finished, relative to the onset of the go signal. To estimate stop signal reaction time (the time at which stopping finished relative to the stop signal), stop-signal delay is subtracted from this value. This is done for each subject for each delay, and the resulting mean taken for lesion and sham groups.

SSRT can also be estimated using a staircase tracking procedure (e.g., Aron et al. 2003a), in which the initial position of the stop signal (Fig. d) is adjusted to be closer to the mean GoRT following a correct stop trial, but adjusted to be further away from the mean GoRT following an incorrect stop trial (Fig. e), resulting, over the course of many trials, in the stop signal position settling at a point at which $50 \%$ of stop trials are performed correctly (Fig. f). At this point, subtraction of the SSD from the median GoRT gives an estimate of the SSRT.

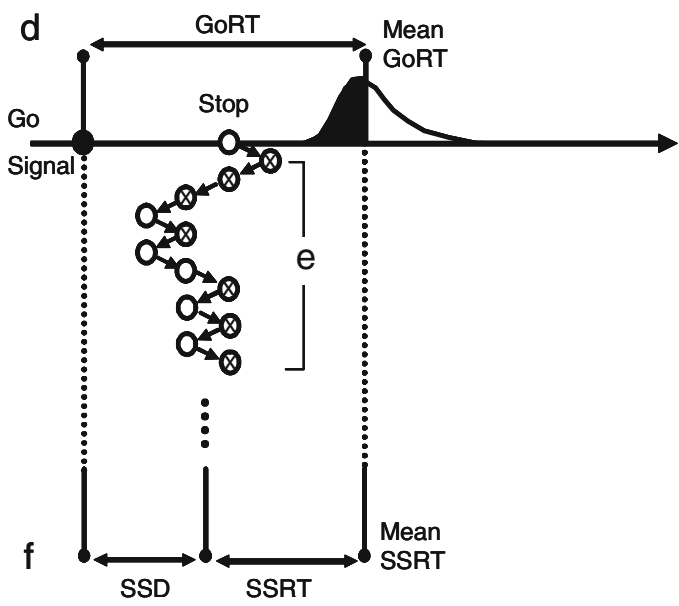

Control for differences in baseline performance.

In the stop-signal task, errors on stop trials may occasionally occur as a result of failed attentional or response selection processes that are unrelated to the speed of the stop process. These errors can be detected on nodelay (no-go) trials as changes in performance accuracy. Inhibition function data can be corrected for baseline differences in performance using the procedure presented in the SSRT task for rats, summarised in Eagle and Robbins 2003a, or using alternative procedures presented in Tannock et al. (1989) and Solanto et al. (2001).

\section{References}

Anderson IM, Clark L, Elliott R, Kulkarni B, Williams SR, Deakin JF (2002) 5 -HT(2C) receptor activation by $m$-chlorophenylpiperazine detected in humans with fMRI. Neuroreport 13:1547-1551

Arnsten AF (2006) Stimulants: therapeutic actions in ADHD. Neuropsychopharmacology 31:2376-83
Arnsten AF, Dudley AG (2005) Methylphenidate improves prefrontal cortical cognitive function through alpha2 adrenoceptor and dopamine D1 receptor actions: Relevance to therapeutic effects in attention deficit hyperactivity disorder. Behav Brain Funct 1:2

Arnsten AF, Li BM (2005) Neurobiology of executive functions: catecholamine influences on prefrontal cortical functions. Biol Psychiatry 57:1377-1384

Aron AR (2007) The neural basis of inhibition in cognitive control. Neuroscientist 13:214-228

Aron AR, Poldrack RA (2005) The cognitive neuroscience of response inhibition: relevance for genetic research in attentiondeficit/hyperactivity disorder. Biol Psychiatry 57:1285-1292

Aron AR, Poldrack RA (2006) Cortical and subcortical contributions to Stop signal response inhibition: role of the subthalamic nucleus. J Neurosci 26:2424-2433

Aron AR, Dowson JH, Sahakian BJ, Robbins TW (2003a) Methylphenidate improves response inhibition in adults with attentiondeficit/hyperactivity disorder. Biol Psychiatry 54:1465-1468

Aron AR, Fletcher PC, Bullmore ET, Sahakian BJ, Robbins TW (2003b) Stop-signal inhibition disrupted by damage to right inferior frontal gyrus in humans. Nat Neurosci 6:115-116

Aron AR, Robbins TW, Poldrack RA (2004) Inhibition and the right inferior frontal cortex. Trends Cogn Sci 8:170-177

Axelrod J, Mueller RA, Henry JP, Stephens PM (1970) Changes in enzymes involved in the biosynthesis and metabolism of noradrenaline and adrenaline after psychosocial stimulation. Nature 225:1059-1060

Band GPH, van Boxtel GJM (1999) Inhibitory motor control in stop paradigms: review and reinterpretation of neural mechanisms. Acta Psychol 101:179-211

Barkley RA (1997) Behavioral inhibition, sustained attention, and executive functions: constructing a unifying theory of ADHD. Psychol Bull 121:65-94

Bastuji H, Jouvet M (1988) Successful treatment of idiopathic hypersomnia and narcolepsy with modafinil. Prog Neuropsychopharmacol Biol Psychiatry 12:695-700

Bedard AC, Ickowicz A, Logan GD, Hogg-Johnson S, Schachar R, Tannock R (2003) Selective inhibition in children with attentiondeficit hyperactivity disorder off and on stimulant medication. J Abnorm Child Psychol 31:315-327

Bellgrove MA, Chambers CD, Vance A, Hall N, Karamitsios M, Bradshaw JL (2006) Lateralized deficit of response inhibition in early-onset schizophrenia. Psychol Med 36:495-505

Bentivoglio M, Morelli M (2005) The organization and circuits of mesencephalic dopaminergic neurons and the distribution of dopamine receptors in the brain. In: Dunnet SB, Bentivoglio M, Bjorklund A, Hokfelt $\mathrm{T}$ (eds) Handbook of chemical neuroanatomy, vol 21. Dopamine. Elsevier, Amsterdam, pp 1-107

Billiard M, Besset A, Montplaisir J, Laffont F, Goldenberg F, Weill JS, Lubin S (1994) Modafinil: a double-blind multicentric study. Sleep 17:S107-S112

Bjork JM, Dougherty DM, Moeller FG, Cherek DR, Swann AC (1999) The effects of tryptophan depletion and loading on laboratory aggression in men: time course and a food-restricted control. Psychopharmacology (Berl) 142:24-30

Bjork JM, Dougherty DM, Moeller FG, Swann AC (2000) Differential behavioral effects of plasma tryptophan depletion and loading in aggressive and nonaggressive men. Neuropsychopharmacology 22:357-369

Boonstra AM, Kooij JJ, Oosterlaan J, Sergeant JA, Buitelaar JK (2005) Does methylphenidate improve inhibition and other cognitive abilities in adults with childhood-onset ADHD? J Clin Exp Neuropsychol 27:278-298

Bunge SA, Dudukovic NM, Thomason ME, Vaidya CJ, Gabrieli JD (2002) Immature frontal lobe contributions to cognitive control in children: evidence from fMRI. Neuron 33:301-311 
Bymaster FP, Katner JS, Nelson DL, Hemrick-Luecke SK, Threlkeld PG, Heiligenstein JH, Morin SM, Gehlert DR, Perry KW (2002) Atomoxetine increases extracellular levels of norepinephrine and dopamine in prefrontal cortex of rat: a potential mechanism for efficacy in attention deficit/hyperactivity disorder. Neuropsychopharmacology 27:699-711

Cantwell DP (1996) Attention deficit disorder: a review of the past 10 years. J Am Acad Child Adolesc Psychiatry 35:978-987

Cardinal RN (2006) Neural systems implicated in delayed and probabilistic reinforcement. Neural Netw 19:1277-1301

Cardinal RN, Winstanley CA, Robbins TW, Everitt BJ (2004) Limbic corticostriatal systems and delayed reinforcement. Ann N Y Acad Sci 1021:33-50

Castellanos FX, Sonuga-Barke EJ, Milham MP, Tannock R (2006) Characterizing cognition in ADHD: beyond executive dysfunction. Trends Cogn Sci 10:117-123

Chamberlain SR, Sahakian BJ (2007) The neuropsychiatry of impulsivity. Curr Opin Psychiatry 20:255-261

Chamberlain SR, Fineberg NA, Blackwell AD, Robbins TW, Sahakian BJ (2006a) Motor inhibition and cognitive flexibility in obsessive-compulsive disorder and trichotillomania. Am J Psychiatry 163:1282-1284

Chamberlain SR, Muller U, Blackwell AD, Clark L, Robbins TW, Sahakian BJ (2006b) Neurochemical modulation of response inhibition and probabilistic learning in humans. Science 311:861-863

Chamberlain SR, Muller U, Deakin JB, Corlett PR, Dowson J, Cardinal RN, Aitken MR, Robbins TW, Sahakian BJ (2007) Lack of deleterious effects of buspirone on cognition in healthy male volunteers. J Psychopharmacol 21:210-215

Clark L, Roiser JP, Cools R, Rubinsztein DC, Sahakian BJ, Robbins TW (2005) Stop signal response inhibition is not modulated by tryptophan depletion or the serotonin transporter polymorphism in healthy volunteers: implications for the 5-HT theory of impulsivity. Psychopharmacology (Berl) 182:570-578

Clarke HF, Walker SC, Crofts HS, Dalley JW, Robbins TW, Roberts AC (2005) Prefrontal serotonin depletion affects reversal learning but not attentional set shifting. J Neurosci 25:532-538

Cleare AJ, Bond AJ (1995) The effect of tryptophan depletion and enhancement on subjective and behavioural aggression in normal male subjects. Psychopharmacology (Berl) 118:72-81

Crean J, Richards JB, de Wit H (2002) Effect of tryptophan depletion on impulsive behavior in men with or without a family history of alcoholism. Behav Brain Res 136:349-357

Dalley JW, Theobald DE, Eagle DM, Passetti F, Robbins TW (2002) Deficits in impulse control associated with tonically-elevated function in rat serotonergic prefrontal cortex. Neuropsychopharmacology 26:716-728

Dalley JW, Cardinal RN, Robbins TW (2004) Prefrontal executive and cognitive functions in rodents: neural and neurochemical substrates. Neurosci Biobehav Rev 28:771-784

Davids E, Zhang K, Tarazi FI, Baldessarini RJ (2003) Animal models of attention-deficit hyperactivity disorder. Brain Res Brain Res Rev 42:1-21

de Wit H, Crean J, Richards JB (2000) Effects of D-amphetamine and ethanol on a measure of behavioral inhibition in humans. Behav Neurosci 114:830-837

de Wit H, Enggasser JL, Richards JB (2002) Acute administration of D-amphetamine decreases impulsivity in healthy volunteers. Neuropsychopharmacology 27:813-825

Decary A, Richer F (1995) Response selection deficits in frontal excisions. Neuropsychologia 33:1243-53

Del-Ben CM, Deakin JF, McKie S, Delvai NA, Williams SR, Elliott R, Dolan M, Anderson IM (2005) The effect of citalopram pretreatment on neuronal responses to neuropsychological tasks in normal volunteers: an FMRI study. Neuropsychopharmacology $30: 1724-1734$
Drewe E (1975) Go- no go learning after frontal lobe lesions in humans. Cortex 11:8-16

Durston S, Fossella JA, Mulder MJ, Casey BJ, Ziermans TB, Vessaz MN, Van Engeland H (2008) Dopamine transporter genotype conveys familial risk of attention-deficit/hyperactivity disorder through striatal activation. J Am Acad Child Adolesc Psych 47:61-67

Eagle DM, Robbins TW (2003a) Inhibitory control in rats performing a stop-signal reaction-time task: effects of lesions of the medial striatum and D-amphetamine. Behav Neurosci 117:1302-1317

Eagle DM, Robbins TW (2003b) Lesions of the medial prefrontal cortex or nucleus accumbens core do not impair inhibitory control in rats performing a stop-signal reaction time task. Behav Brain Res 146:131-144

Eagle DM, Tufft MR, Goodchild HL, Robbins TW (2007) Differential effects of modafinil and methylphenidate on stop-signal reaction time task performance in the rat, and interactions with the dopamine receptor antagonist cis-flupenthixol. Psychopharmacology (Berl) 192:193-206

Eagle DM, Baunez C, Hutcheson DM, Lehmann O, Shah AP, Robbins TW (2008) Stop-signal reaction time task performance: role of prefrontal cortex and subthalamic nucleus. Cereb Cortex 18:178188 DOI $10.1093 /$ cercor/bhm044

Eichenbaum H, Clegg RA, Feeley A (1983) Reexamination of functional subdivisions of the rodent prefrontal cortex. Exp Neurol 79:434-451

Eichenbaum H, Shedlack KJ, Eckmann KW (1980) Thalamocortical mechanisms in odor-guided behavior. I. Effects of lesions of the mediodorsal thalamic nucleus and frontal cortex on olfactory discrimination in the rat. Brain Behav Evol 17:255-275

Evenden JL (1999) The pharmacology of impulsive behaviour in rats VII: the effects of serotonergic agonists and antagonists on responding under a discrimination task using unreliable visual stimuli. Psychopharmacology (Berl) 146:422-431

Evenden JL, Ryan CN (1996) The pharmacology of impulsive behaviour in rats: the effects of drugs on response choice with varying delays of reinforcement. Psychopharmacology (Berl) 128:161-170

Feola TW, de Wit H, Richards JB (2000) Effects of D-amphetamine and alcohol on a measure of behavioral inhibition in rats. Behav Neurosci 114:838-848

Fillmore MT, Rush CR (2002) Impaired inhibitory control of behavior in chronic cocaine users. Drug Alcohol Depend 66:265-273

Fillmore MT, Rush CR, Hays L (2002) Acute effects of oral cocaine on inhibitory control of behavior in humans. Drug Alcohol Depend 67:157-167

Fillmore MT, Kelly TH, Martin CA (2005) Effects of D-amphetamine in human models of information processing and inhibitory control. Drug Alcohol Depend 77:151-159

Fillmore MT, Rush CR, Hays L (2006) Acute effects of cocaine in two models of inhibitory control: implications of non-linear dose effects. Addiction 101:1323-1332

Frank MJ, O'Reilly RC (2006) A mechanistic account of striatal dopamine function in human cognition: psychopharmacological studies with cabergoline and haloperidol. Behav Neurosci 120:497-517

Frank MJ, Santamaria A, O'Reilly RC, Willcutt E (2006) Testing computational models of dopamine and noradrenaline dysfunction in attention deficit/hyperactivity disorder. Neuropsychopharmacology 32:1583-1599

Fuster JM (1988) The prefrontal cortex: anatomy, physiology and neuropsychology of the frontal lobe. Raven, New York

Gainetdinov RR, Wetsel WC, Jones SR, Levin ED, Jaber M, Caron MG (1999) Role of serotonin in the paradoxical calming effect of psychostimulants on hyperactivity. Science 283:397-401

Garavan H, Ross TJ, Stein EA (1999) Right hemispheric dominance of inhibitory control: an event-related functional MRI study. Proc Natl Acad Sci USA 96:8301-8306 
Gauggel S, Rieger M, Feghoff TA (2004) Inhibition of ongoing responses in patients with Parkinson's disease. J Neurol Neurosurg Psychiatry 75:539-544

Godefroy O, Rousseaux M (1996) Divided and focused attention in patients with lesion of the prefrontal cortex. Brain Cogn 30:155-174

Graham S, Ho MY, Bradshaw CM, Szabadi E (1994) Facilitated acquisition of a temporal discrimination following destruction of the ascending 5-hydroxytryptaminergic pathways. Psychopharmacology (Berl) 116:373-378

Groenewegen HJ, Schilman EA, Joel D, Uylings HBM (2005) The orbitofrontal cortex in rats projects to central parts of the caudateputamen and to a lesser extent to the ventral striatum. Society for Neuroscience, Washington, DC

Harnishfeger K (1995) Development of cognitive inhibition. In: Dempster F, Brainerd C (eds) Interference and inhibition in cognition. Academic, San Diego, CA, pp 175-204

Harrison AA, Everitt BJ, Robbins TW (1997) Central 5-HT depletion enhances impulsive responding without affecting the accuracy of attentional performance: interactions with dopaminergic mechanisms. Psychopharmacology (Berl) 133:329-342

Harrison AA, Everitt BJ, Robbins TW (1999) Central serotonin depletion impairs both the acquisition and performance of a symmetrically reinforced go/no-go conditional visual discrimination. Behav Brain Res 100:99-112

Hausknecht KA, San George M, Gancarz AM, Ashrafioun L, De Wit H, Zhuang Z, Richards JB (2006) Impulsivity in serotonin transporter knock-out mice: effects of methylphenidate. Program No. 749.8/Y12 2006 Neuroscience Meeting Planner, Society for Neuroscience, Atlanta, GA

Hendley ED, Snyder SH, Fauley JJ, LaPidus JB (1972) Stereoselectivity of catecholamine uptake by brain synaptosomes: studies with ephedrine, methylphenidate and phenyl-2-piperidyl carbinol. J Pharmacol Exp Ther 183:103-116

Hershey T, Black KJ, Hartlein J, Braver TS, Barch DM, Carl JL, Perlmutter JS (2004) Dopaminergic modulation of response inhibition: an fMRI study. Brain Res Cogn Brain Res 20:438-448

Hoover WB, Vertes RP (2004) Efferent projections of the ventral frontal polar cortex. Society for Neuroscience, San Diego, CA

Inase M, Li BM, Tanji J (1997) Dopaminergic modulation of neuronal activity in the monkey putamen through D1 and D2 receptors during a delayed Go/Nogo task. Exp Brain Res 117:207-218

Iversen SD, Mishkin M (1970) Perseverative interference in monkeys following selective lesions of the inferior prefrontal convexity. Exp Brain Res 11:376-386

Konishi S, Nakajima K, Uchida I, Sekihara K, Miyashita Y (1998) No-go dominant brain activity in human inferior prefrontal cortex revealed by functional magnetic resonance imaging. Eur J Neurosci 10:1209-1213

Konishi S, Nakajima K, Uchida I, Kikyo H, Kameyama M, Miyashita Y (1999) Common inhibitory mechanism in human inferior prefrontal cortex revealed by event-related functional MRI. Brain 122(Pt 5):981-991

Koskinen T, Ruotsalainen S, Sirvio J (2000) The 5-HT(2) receptor activation enhances impulsive responding without increasing motor activity in rats. Pharmacol Biochem Behav 66:729-738

Krause J, la Fougere C, Krause KH, Ackenheil M, Dresel SH (2005) Influence of striatal dopamine transporter availability on the response to methylphenidate in adult patients with ADHD. Eur Arch Psychiatry Clin Neurosci 255:428-431

Kuczenski R, Segal DS (1997) Effects of methylphenidate on extracellular dopamine, serotonin, and norepinephrine: comparison with amphetamine. J Neurochem 68:2032-2037

Langley K, Marshall L, van den Bree M, Thomas H, Owen M, O'Donovan M, Thapar A (2004) Association of the dopamine D4 receptor gene 7-repeat allele with neuropsychological test performance of children with ADHD. Am J Psychiatry 161:133-138
LeMarquand DG, Benkelfat C, Pihl RO, Palmour RM, Young SN (1999) Behavioral disinhibition induced by tryptophan depletion in nonalcoholic young men with multigenerational family histories of paternal alcoholism. Am J Psychiatry 156:1771-1779

Lewis DA (2001) The catecholaminergic innervation of primate cerebral cortex. In: Solanto MV, Arnsten AF, Castellanos FX (eds) Stimulant drugs and ADHD. OUP, Oxford, pp 77-103

Leyton M, Okazawa H, Diksic M, Paris J, Rosa P, Mzengeza S, Young SN, Blier P, Benkelfat C (2001) Brain regional alpha[11C]methyl-L-tryptophan trapping in impulsive subjects with borderline personality disorder. Am J Psychiatry 158:775-782

Leyton M, aan het Rot M, Booij L, Baker GB, Young SN, Benkelfat C (2007) Mood-elevating effects of D-amphetamine and incentive salience: the effect of acute dopamine precursor depletion. J Psychiatry Neurosci 32:129-136

Li BM, Kubota K (1998) Alpha-2 adrenergic modulation of prefrontal cortical neuronal activity related to a visual discrimination task with GO and NO-GO performances in monkeys. Neurosci Res 31:83-95

Lijffijt M, Kenemans JL, ter Wal A, Quik EH, Kemner C, Westenberg H, Verbaten MN, van Engeland H (2006) Dose-related effect of methylphenidate on stopping and changing in children with attention-deficit/hyperactivity disorder. Eur Psychiatry 21:544-547

Lister S, Pearce JM, Butcher SP, Collard KJ, Foster GA (1996) Acquisition of conditioned inhibition in rats is impaired by ablation of serotoninergic pathways. Eur J Neurosci 8:415-423

Logan GD (1994) On the ability to inhibit thought and action. A users' guide to the stop signal paradigm. In: Dagenbach D, Carr $\mathrm{TH}$ (eds) Inhibitory processes in attention, memory and language. Academic, San Diego, CA, pp 189-236

Logan GD, Cowan WB (1984) On the ability to inhibit thought and action - a theory of an act of control. Psychol Rev 91:295-327

Lou HC, Henriksen L, Bruhn P, Borner H, Nielsen JB (1989) Striatal dysfunction in attention deficit and hyperkinetic disorder. Arch Neurol 46:48-52

Ma CL, Qi XL, Peng JY, Li BM (2003) Selective deficit in no-go performance induced by blockade of prefrontal cortical alpha 2adrenoceptors in monkeys. Neuroreport 14:1013-1016

MacLeod CM, Dodd MD, Sheard ED, Wilson DE, Bibi U (2003) In opposition to inhibition. In: Ross BH (ed) The psychology of learning and motivation. Academic, San Diego, CA, pp 163-214

Masaki D, Yokoyama C, Kinoshita S, Tsuchida H, Nakatomi Y, Yoshimoto K, Fukui K (2006) Relationship between limbic and cortical 5-HT neurotransmission and acquisition and reversal learning in a go/no-go task in rats. Psychopharmacology (Berl) 189:249-258

Menon V, Adleman NE, White CD, Glover GH, Reiss AL (2001) Error-related brain activation during a Go/NoGo response inhibition task. Hum Brain Mapp 12:131-143

Mesulam MM, Mufson EJ, Levey AI, Wainer BH (1983) Central cholinergic pathways in the rat: an overview based on alternative nomenclature. Neuroscience 10:1185-1201

Minzenberg MJ, Carter CS (2008) Modafinil: a review of neurochemical actions and effects on cognition. Neuropsychopharmacology 33 (7):1477-1502

Mobini S, Chiang TJ, Ho MY, Bradshaw CM, Szabadi E (2000) Effects of central 5-hydroxytryptamine depletion on sensitivity to delayed and probabilistic reinforcement. Psychopharmacology (Berl) 152:390-397

Moeller FG, Dougherty DM, Swann AC, Collins D, Davis CM, Cherek DR (1996) Tryptophan depletion and aggressive responding in healthy males. Psychopharmacology (Berl) 126:97-103

Monterosso JR, Aron AR, Cordova X, Xu J, London ED (2005) Deficits in response inhibition associated with chronic methamphetamine abuse. Drug Alcohol Depend 79:273-277

Muller U, Clark L, Lam ML, Moore RM, Murphy CL, Richmond NK, Sandhu RS, Wilkins IA, Menon DK, Sahakian BJ, Robbins TW 
(2005) Lack of effects of guanfacine on executive and memory functions in healthy male volunteers. Psychopharmacology (Berl) 182:205-213

Murphy FC, Smith KA, Cowen PJ, Robbins TW, Sahakian BJ (2002) The effects of tryptophan depletion on cognitive and affective processing in healthy volunteers. Psychopharmacology (Berl) $163: 42-53$

Nigg JT, Blaskey LG, Stawicki JA, Sachek J (2004) Evaluating the endophenotype model of ADHD neuropsychological deficit: results for parents and siblings of children with ADHD combined and inattentive subtypes. J Abnorm Psychology 113:614-625

Nomura M, Nomura Y (2006) Psychological, neuroimaging, and biochemical studies on functional association between impulsive behavior and the 5-HT2A receptor gene polymorphism in humans. Ann N Y Acad Sci 1086:134-143

Oosterlaan J, Logan GD, Sergeant JA (1998) Response inhibition in $\mathrm{AD} / \mathrm{HD}, \mathrm{CD}$, comorbid $\mathrm{AD} / \mathrm{HD}+\mathrm{CD}$, anxious, and control children: a meta-analysis of studies with the stop task. J Child Psychol Psychiatry 39:411-425

Overtoom CC, Verbaten MN, Kemner C, Kenemans JL, van Engeland $\mathrm{H}$, Buitelaar JK, van der Molen MW, van der Gugten J, Westenberg H, Maes RA, Koelega HS (2003) Effects of methylphenidate, desipramine, and L-dopa on attention and inhibition in children with attention deficit hyperactivity disorder. Behav Brain Res 145:7-15

Passetti F, Dalley JW, Robbins TW (2003) Double dissociation of serotonergic and dopaminergic mechanisms on attentional performance using a rodent five-choice reaction time task. Psychopharmacology (Berl) 165:136-145

Paule MG, Rowland AS, Ferguson SA, Chelonis JJ, Tannock R, Swanson JM, Castellanos FX (2000) Attention deficit/hyperactivity disorder: characteristics, interventions and models. Neurotoxicol Teratol 22:631-651

Penades R, Catalan R, Rubia K, Andres S, Salamero M, Gasto C (2007) Impaired response inhibition in obsessive compulsive disorder. Eur Psychiatry 22:404-410

Pihl RO, Young SN, Harden P, Plotnick S, Chamberlain B, Ervin FR (1995) Acute effect of altered tryptophan levels and alcohol on aggression in normal human males. Psychopharmacology (Berl) 119:353-360

Preuss TM (1995) Do rats have a prefrontal cortex? The RoseWoolsey-Akert program reconsidered. J Cogn Neurosci 7:1-24

Riedel WJ (2004) Cognitive changes after acute tryptophan depletion: what can they tell us? Psychol Med 34:3-8

Rieger M, Gauggel S, Burmeister K (2003) Inhibition of ongoing responses following frontal, nonfrontal, and basal ganglia lesions. Neuropsychology 17:272-282

Robbins TW (1998) Homology in behavioural pharmacology: an approach to animal models of human cognition. Behav Pharmacol 9:509-519

Robbins TW (2002) The 5-choice serial reaction time task: behavioural pharmacology and functional neurochemistry. Psychopharmacology (Berl) 163:362-380

Robbins TW (2007) Shifting and stopping: fronto-striatal substrates, neurochemical modulation and clinical implications. Philos Trans R Soc Lond B Biol Sci 362:917-932

Robbins TW, Everitt BJ (1987) Comparative functions of the central noradrenergic, dopaminergic and cholinergic systems. Neuropharmacology 26:893-901

Robbins TW, Clark L, Clarke HF, Roberts AC (2006) Neurochemical modulation of orbitofrontal cortex function. In: Zald D, Rauch SL (eds) The orbitofrontal cortex. Oxford University Press, London, pp 393-422

Robinson ES, Eagle DM, Mar AC, Bari A, Banerjee G, Jiang X, Dalley JW, Robbins TW (2008) Similar effects of the selective noradrenaline reuptake inhibitor atomoxetine on three distinct forms of impulsivity in the rat. Neuropsychopharmacology 33 (5):1028-1037

Rosa-Neto P, Lou HC, Cumming P, Pryds O, Karrebaek H, Lunding J, Gjedde A (2005) Methylphenidate-evoked changes in striatal dopamine correlate with inattention and impulsivity in adolescents with attention deficit hyperactivity disorder. Neuroimage $25: 868-876$

Ross SB (1978) Antagonism by methylphenidate of the stereotyped behaviour produced by $(+)$-amphetamine in reserpinized rats. $\mathrm{J}$ Pharm Pharmacol 30:253-254

Rubia K, Oosterlaan J, Sergeant JA, Brandeis D, v Leeuwen T (1998) Inhibitory dysfunction in hyperactive boys. Behav Brain Res 94:25-32

Rubia K, Russell T, Overmeyer S, Brammer MJ, Bullmore ET, Sharma T, Simmons A, Williams SC, Giampietro V, Andrew CM, Taylor E (2001) Mapping motor inhibition: conjunctive brain activations across different versions of go/no-go and stop tasks. Neuroimage 13:250-261

Rubia K, Smith AB, Brammer MJ, Taylor E (2003) Right inferior prefrontal cortex mediates response inhibition while mesial prefrontal cortex is responsible for error detection. Neuroimage 20:351-358

Rubia K, Lee F, Cleare AJ, Tunstall N, Fu CH, Brammer M, McGuire $\mathrm{P}$ (2005a) Tryptophan depletion reduces right inferior prefrontal activation during response inhibition in fast, event-related fMRI. Psychopharmacology (Berl) 179:791-803

Rubia K, Smith AB, Brammer MJ, Toone B, Taylor E (2005b) Abnormal brain activation during inhibition and error detection in medication-naive adolescents with ADHD. Am J Psychiatry 162:1067-1075

Rubia K, Smith AB, Woolley J, Nosarti C, Heyman I, Taylor E, Brammer M (2006a) Progressive increase of frontostriatal brain activation from childhood to adulthood during event-related tasks of cognitive control. Hum Brain Mapp 27:973-993

Rubia K, Taylor E, Asherton P, Curran S (2006b) Association between specific inhibitory measures and the 7-repeat allele of the dopamine D4 receptor gene in attention deficit hyperactivity disorder. In: Oades RD (ed) Attention deficit/hyperactivity disorder (ADHD) and the hyperkinetic syndrome: current ideas and ways forward. Nova Science, NY

Rubia K, Smith A, Taylor E (2007) Performance of children with attention deficit hyperactivity disorder (ADHD) on a test battery of impulsiveness. Child Neuropsychol 13:276-304

Rubinsztein JS, Rogers RD, Riedel WJ, Mehta MA, Robbins TW, Sahakian BJ (2001) Acute dietary tryptophan depletion impairs maintenance of "affective set" and delayed visual recognition in healthy volunteers. Psychopharmacology (Berl) 154:319-326

Rugino TA, Copley TC (2001) Effects of modafinil in children with attention-deficit/hyperactivity disorder: an open-label study. J Am Acad Child Adolesc Psych 40:230-235

Rugino TA, Samsock TC (2003) Modafinil in children with attentiondeficit hyperactivity disorder. Pediatr Neurol 29:136-142

Ruotsalainen S, Sirvio J, Jakala P, Puumala T, MacDonald E, Riekkinen P Sr. (1997) Differential effects of three 5-HT receptor antagonists on the performance of rats in attentional and working memory tasks. Eur Neuropsychopharmacol 7:99-108

Salomon RM, Mazure CM, Delgado PL, Mendia P, Charney DS (1994) Serotonin function in aggression: the effect of acute plasma tryptophan depletion in aggressive patients. Biol Psychiatry 35:570-572

Schachar R, Tannock R, Marriott M, Logan G (1995) Deficient inhibitory control in attention deficit hyperactivity disorder. J Abnorm Child Psychol 23:411-437

Schachar R, Logan GD, Robaey P, Chen S, Ickowicz A, Barr C (2007) Restraint and cancellation: multiple inhibition deficits in attention deficit hyperactivity disorder. J Abnorm Child Psychol 35:229-238 
Schilman EA, Uylings HB, Graaf YG, Joel D, Groenewegen HJ (2007) The orbital cortex in rats topographically projects to central parts of the caudate-putamen complex. Neurosci Lett 432:40-45

Schoenbaum G, Nugent SL, Saddoris MP, Setlow B (2002) Orbitofrontal lesions in rats impair reversal but not acquisition of go, no-go odor discriminations. Neuroreport 13:885-890

Solanto MV (1986) Behavioral effects of low-dose methylphenidate in childhood attention deficit disorder: implications for a mechanism of stimulant drug action. J Am Acad Child Adolesc Psych 25:96-101

Solanto MV (1998) Neuropsychopharmacological mechanisms of stimulant drug action in attention-deficit hyperactivity disorder: a review and integration. Behav Brain Res 94:127-152

Soubrie P (1986) Reconciling the role of central serotonin neurons in human and animal behavior. Behav Brain Sci 9:319-364

Spencer T, Biederman J, Wilens T, Faraone S, Prince J, Gerard K, Doyle R, Parekh A, Kagan J, Bearman SK (2001) Efficacy of a mixed amphetamine salts compound in adults with attentiondeficit/hyperactivity disorder. Arch Gen Psychiatry 58:775-782

Tannock R, Schachar RJ, Carr RP, Chajczyk D, Logan GD (1989) Effects of methylphenidate on inhibitory control in hyperactive children. J Abnorm Child Psychol 17:473-491

Taylor FB, Russo J (2000) Efficacy of modafinil compared to dextroamphetamine for the treatment of attention deficit hyperactivity disorder in adults. J Child Adolesc Psychopharmacol 10:311-320

Turner D (2006) A review of the use of modafinil for attention-deficit hyperactivity disorder. Expert Rev Neurother 6:455-468

Turner DC, Robbins TW, Clark L, Aron AR, Dowson J, Sahakian BJ (2003) Cognitive enhancing effects of modafinil in healthy volunteers. Psychopharmacology (Berl) 165:260-269

Turner DC, Clark L, Dowson J, Robbins TW, Sahakian BJ (2004) Modafinil improves cognition and response inhibition in adult attention-deficit/hyperactivity disorder. Biol Psychiatry 55:10311040

Vaidya CJ, Austin G, Kirkorian G, Ridlehuber HW, Desmond JE, Glover GH, Gabrieli JD (1998) Selective effects of methylphenidate in attention deficit hyperactivity disorder: a functional magnetic resonance study. Proc Natl Acad Sci USA 95:14494 14499

Vaidya CJ, Bunge SA, Dudukovic NM, Zalecki CA, Elliott GR, Gabrieli JD (2005) Altered neural substrates of cognitive control in childhood ADHD: evidence from functional magnetic resonance imaging. Am J Psychiatry 162:1605-1613

Van den Bergh F, Spronk M, Ferreira L, Bloemarts E, Groenink L, Olivier B, Oosting R (2006) Relationship of delay aversion and response inhibition to extinction learning, aggression, and sexual behaviour. Behav Brain Res 175:75-81 van den Wildenberg WP, van Boxtel GJ, van der Molen MW, Bosch DA, Speelman JD, Brunia CH (2006) Stimulation of the subthalamic region facilitates the selection and inhibition of motor responses in Parkinson's disease. J Cogn Neurosci $18: 626-636$

Volkow ND, Wang GJ, Fowler JS, Logan J, Angrist B, Hitzemann R, Lieberman J, Pappas N (1997) Effects of methylphenidate on regional brain glucose metabolism in humans: relationship to dopamine D2 receptors. Am J Psychiatry 154:50-65

Volkow ND, Wang G, Fowler JS, Logan J, Gerasimov M, Maynard L, Ding Y, Gatley SJ, Gifford A, Franceschi D (2001) Therapeutic doses of oral methylphenidate significantly increase extracellular dopamine in the human brain. J Neurosci 21:RC121

Vollm B, Richardson P, McKie S, Elliott R, Deakin JF, Anderson IM (2006) Serotonergic modulation of neuronal responses to behavioural inhibition and reinforcing stimuli: an fMRI study in healthy volunteers. Eur J Neurosci 23:552-560

Vrshek-Schallhorn S, Wahlstrom D, Benolkin K, White T, Luciana M (2006) Affective bias and response modulation following tyrosine depletion in healthy adults. Neuropsychopharmacology $31: 2523-2536$

Wade TR, de Wit H, Richards JB (2000) Effects of dopaminergic drugs on delayed reward as a measure of impulsive behavior in rats. Psychopharmacology (Berl) 150:90-101

Walderhaug E, Lunde H, Nordvik JE, Landro NI, Refsum H, Magnusson A (2002) Lowering of serotonin by rapid tryptophan depletion increases impulsiveness in normal individuals. Psychopharmacology (Berl) 164:385-391

Ward BO, Wilkinson LS, Robbins TW, Everitt BJ (1999) Forebrain serotonin depletion facilitates the acquisition and performance of a conditional visual discrimination task in rats. Behav Brain Res 100:51-65

Waters KA, Burnham KE, O'Connor D, Dawson GR, Dias R (2005) Assessment of modafinil on attentional processes in a five-choice serial reaction time test in the rat. J Psychopharmacol 19:149-158

Winstanley CA, Dalley JW, Theobald DE, Robbins TW (2004a) Fractionating impulsivity: contrasting effects of central 5-HT depletion on different measures of impulsive behavior. Neuropsychopharmacology 29:1331-1343

Winstanley CA, Theobald DE, Dalley JW, Glennon JC, Robbins TW (2004b) 5-HT2A and 5-HT2C receptor antagonists have opposing effects on a measure of impulsivity: interactions with global 5-HT depletion. Psychopharmacology (Berl) 176:376-385

Winstanley CA, Eagle DM, Robbins TW (2006) Behavioral models of impulsivity in relation to ADHD: translation between clinical and preclinical studies. Clin Psychol Rev 26:379-395

Wise RA, Bozarth MA (1987) A psychomotor stimulant theory of addiction. Psychol Rev 94:469-492 